\title{
FRAY CRISTOBAL CABALLERO Y LA PORTADA DE LA MERCED DE LIMA
}

\section{1.-Fuentes documentales acerca de fray Cristóbal Caballero}

Las informaciones hasta ahora conocidas acerca del artífice mercedario fray Cristóbal Caballero se limitan a las someras alusiones de Vargas Ugarte en su Ensayo de diccionario, ' imposibles de verificar en sus fuentes documentales por no ir acompañadas de las referencias a los textos originales; $y$ a las que por su parte aportó Harth-Terré en un estudio publicado varias veces e incluido en su obra Escultores españoles. ${ }^{2} \mathrm{El}$ acopio de datos en estos dos estudios es muy parco y no siempre fiable; tanto que no permiten conocer la obra profesional realizada por el alarife y ensamblador limeño fray Cristóbal Caballero durante la segunda mitad del siglo XVII en Lima.

Aventuró Harth-Terré la opinión de que el mercedario Caballero era español de nacimiento, oriundo de Extremadura; y ello sobre la base de una fuente documental leída apresuradamente. Escribe así Harth-Terré: «Era Cristóbal hijo de don Diego Caballero natural de Zalamea de la Serena, en la provincia de Extremadura, quien al fallecer le había dejado regular fortuna, pues según el testamento de don Diego, se descubre que era acaudalado y tenía varias hermanas todas ellas que habían ingresado a las órdenes religiosas». ${ }^{3}$ En realidad, se trata de la lectura errónea del testamento de don Diego Caballero, otorgado con fecha 20 de enero de 1685, en el que nombraba como su albacea y tenedor de bienes al «Padre

1 Vargas Ugarte, R.: Ensayo de un diccionario de artifices coloniales en la América meridional, Burgos, 1968, 2. ${ }^{n}$ ed.

2 Harth-Terré, E.: Escultores españoles en el Virreinato del Perú, Lima, 1977, págs. 196-202.

3 Ibidem, pág. 201. 
Presentado Fray Cristóbal Caballero mi hermano del dicho Orden de las Mercedes». ${ }^{4}$ El tal don Diego Caballero declaró en ese documento reiteradamente que fray Cristóbal era su hermano: y en ningún lugar dice que el mercedario fuera hijo suyo, como ha escrito Harth-Terré. De sus hijos dice don Diego: «...y durante el dicho matrimonio tuvimos y procreamos por nuestros hijos legítimos a doña María = doña Isabel Caballero, monjas profesas de velo negro en el monasterio de Santa Catalina y a Juan Cabaillero los declaro por todos mis hijos legítimos». ${ }^{5}$ Declaraba igualmente él, don Diego, que era «natural de la villa de Zalamea de la Serena en Extremadura hijo legítimo de Cristóbal Caballero y de María Alonso Zenteno difuntos». Consiguientemente, estos mismos deberán ser los padres del mercedario fray Cristóbal Caballero, su hermano.

Quedaría todavía por aclarar el lugar de nacimiento de Cristóbal. Pues bien, he descubierto la partida de nacimiento del niño Cristóbal Caballero, inscrita en el libro de Bautismos de la parroquia limeña del Sagrario de la Catedral. Dice así a la letra: «Xristóbal Caballero. Jueves veinte de marzo de mil y seiscientos treinta y un años yo el doctor Fernando Becerril cura de esta Santa Iglesia bauticé y puse óleo y crisma a Xristóbal de edad de cuarenta días hijo legítimo de Xristóbal Caballero y de María Alonso su mujer, fueron sus padrinos Alonso de Esquivel y Beatriz Alvarez su mujer testigos Tomás Hernández y Juan Pérez». ${ }^{\circ}$ Según aparece en esta partida de bautismo, los padres del niño Cristóbal Caballero son los mismos que los declarados en el testamento de don Diego Caballero, su hermano. Queda, pues, demostrado que el alarife fray Cristóbal Caballero nació en Lima; si tenía cuarenta días cuando le bautizaron el veinte de marzo, se concluye que nació en la Ciudad de los Reyes del Perú el día 14 de febrero de 1631. Es importante tener en cuenta su origen limeño, para interpretar correctamente su obra como alarife y ensamblador de

4 Archivo Arzobispal de Lima. Mercedarios, legajo 9, 1685-1691, sin numeración de folios, fol. 10v.-11r.

5 Ibidem, fol. $4 \mathrm{v}$. folio 69 .

6 Parroquia del Sagrario, Lima, Libro de Bautismos, núm. 5, 1628-1637. 
retablos. Algún historiador de la arquitectura virreinal limeña infirió de los falsos datos de Harth-Terré que fray Cristóbal Caballero al embarcar en Sevilla para las Indias debió conocer el arte de Cano y de los Ribas, llevar su estilo a los retablos limeños. En realidad, fray Cristóbal nació, vivió y murió en Lima, sin haber tenido conocimiento directo de la arquitectura de Sevilla en obra firme y en madera. Sus trabajos deben, pues, ser enjuiciados en función de la arquitectura limeña del siglo XVII que él conoció y en la que participó activamente.

Para su estudio sobre fray Cristóbal Caballero se basó HarthTerré en las escasas actividades del mercedario por él conocidas: una escultura mencionada por Vargas Ugarte sin indicación de la fuente documental; ciertos datos tomados a la ligera acerca de pagos por la hechura del retablo del altar mayor para el monasterio de la Santísima Trinidad, su tarea en el claustro de Santa Catalina también interpretada erróneamente; la reparación del retablo de las Once Mil Vírgenes en el monasterio de la Limpia Concepción, además de algunas tasaciones; y también en el informe acerca de la catedral de Lima publicado por Diego Angulo Iñiguez. ${ }^{7}$ Todos estos datos proceden exclusivamente de los legajos de monasterios del Archivo Arzobispal de Lima; pero no aportan ninguna información procedentes del Archivo General de la Nación en Lima (A.G.N.), que es precisamente donde se conservan los conciertos notariales de las obras realizadas por fray Cristóbal Caballero.

Atribuye Vargas Ugarte al mercedario Caballero la hechura del túmulo puesto en la catedral de Lima para las exequias de la reina madre doña Mariana de Austria. ${ }^{8}$ No he logrado verificar esta información, ya que ninguno de los dos ejemplares de la obra acerca de estas exequias conservados en la Biblioteca Nacional de] Perú guarda el grabado del túmulo; y la barroca descripción yue de él hace el autor de la obra no permite reconstruir su arcluitec-

7 Harth-Terré: Escultores..., 196.202.

8 Vargas Ugarte, R.: Apéndice al Diccionario, 1955, pág. 90. 
tura. ${ }^{9}$ Teniendo en cuenta la fecha tardía de este grabado, podrá descubrirse en él la evolución que experimentó el estilo de fray Cristóbal desde sus primeras obras y el grabado del monumento para el rey Carlos II. El grabado para el túmulo viene a ser casi contemporáneo de la portada de la iglesia de La Merced.

Parece ser que en el archivo del convento de La Merced de Lima no se conservan otros documentos referentes a fray Cristóbal Caballero que las breves y someras referencias que he podido leer en el Libro de Provincia. Tampoco el historiador mercedario padre Víctor Barriga aporta otras noticias acerca del mercedario Caballero que vivió en ese convento limeño.

La limitación en el uso de las fuentes documentales hasta ahora utilizadas por los historiadores contribuye no sólo a menguar el conocimiento de los trabajos ejecutados por fray Cristóbal Caballero; sino también y principalmente a opacar ciertas facetas de su actividad como artífice; ya que Harth-Terré le ha catalogado sólo como escultor. Es justo reconocer que este mercedario dedicó parte de su tiempo a tallar imágenes, como por ejemplo, el bulto de Santa Rosa de Lima que vendió al cabildo metropolitano de Lima para ser colocado en el altar mayor de la catedral, por el precio de 200 pesos con fecha 1 de septiembre de $1694 .{ }^{10} \mathrm{Ya}$ desde su primera obra que de él tengo documentada, se titula «maestro de escultor y ensamblador». Ello acontece en el concierto notarial celebrado con los mayordomos de la cofradía de la Santi Cruz en el convento de Santo Domingo para hacerles unas andas procesionales que debía entregar para el domingo de Ramos siguiente a partir del día 17 de enero de 1657, fecha del concierto, por el precio de 900 pesos de a ocho reales. "Consideramos ésta como su primera obra documentada; pues no es posible confrontar con la fuente documental la talla de una imagen en 1650 que le

9 Romero González de Villalobos, R.: Funeral, pompa y solemnidad en las exequias a la muerte de la Católica y Serenisima Reina Madre doña Mariana rie Austria, Lima, Joseph de Contreras, 1697. El autor del grabado sería el mercedario Pedro Nolasco Mere.

10 Archivo del Cabildo Metropolitano de Lima, Cuenta y data... desde ('l 2 de marzo de 1691 hasta fin de julio de 1696. folio 573.

11 Archivo General de la Nación. Lima. En adelante (A.G.N.), escribano Martín de Ochandiano, 1657, protocolo 1.294, folio 34 . 
atribuye el padre Vargas Ugarte. Pues bien, ya desde los inicios de su actividad artística, aun cuando fray Cristóbal tallaba o arreglaba bultos de imágenes para los retablos que le encomendaban, tal como se observa en los conciertos notariales de obra, destacó principalmente como arquitecto en el ensamblaje de retablos y en la construcción de obra firme, según aparece en los conciertos notariales descubiertos en el Archivo General de la Nación de Lima.

Por un concierto notarial de 5 de junio de 1658, el provincial de La Merced otorgó licencia a fray Cristóbal Caballero «religioso corista y profeso» para que vendiera un esclavo suyo. Dice este documento que «era hijo del convento Grande de Lima», lo que en el lenguaje religioso significaba que había tomado el hábito y profesado como religioso en ese convento limeño. ${ }^{12} \mathrm{No}$ he logrado averiguar en qué fecha ingresó en el convento de La Merced; pero debería ser en edad adulta, pues en la fecha de junio de 1658 tenía 27 años de edad y todavía era corista, es decir, no se había ordenado de sacerdote.

Muy poco tiempo después de la primera obra documentada, concertó el día 28 de septiembre de 1659 la hechura de un retablo por 2.400 pesos para la cofradía de San Lorenzo en la iglesia de su convento de La Merced. Este concierto es importante porque incluye la licencia del Superior religioso por la que estaba autorizado a ejercer estas actividades artísticas. En ella leemos este fragmento: «por cuanto tenemos dado título de maestro de obras de este convento Grande de Lima al Padre fray Cristóbal Caballero por ser primo en el arte de arquitectura y escultura y tener muchas dependencias de obras pertenecientes al dicho oficio». ${ }^{13}$ Es necesario señalar que ya en este concierto notarial presentó como su fiador a su hermano Diego Caballero.

A diferencia de fray Diego Maroto, que permaneció en actividad ininterrumpida como maestro mayor de obras durante toda la segunda mitad del siglo XVII hasta el final de sus días hacia

12 A.G.N., escribano Martín Ochoa, 1657-1663, protocolo 1.300, folio $34 \mathrm{v}$.

13 A.G.N., escribano Joseph del Colro, 1660-1661, protocolo 391, sin numeración de folios.

Tomo XLVIII 
enero de 1696, el mercedario fray Cristóbal Caballero trabajó en la arquitectura con alguna larga interrupción; y sospecho que retornó a ella después de haber concluido su cargo de comendador en el convento de La Merced del Callao, y apremiado por la urgencia de tener que emprender las reconstrucciones de las ruinas producidas por el terremoto de 1687.

Causa un cierto desconcierto la curiosa circunstancia de que algunos retablos, que manifiestamente fueron trazados y ejecutados por fray Cristóbal, aparezcan en los conciertos notariales como obra de su hermano don Diego. De los numerosos conciertos celebrados por este don Diego Caballero se deduce que era un próspero hombre de negocios, pues otorgó abundantes cartas de pago, escrituras de obligación, préstamos a terceros, etc. En cierta ocasión contrajo deuda por una elevada cantidad de pesos, e inmediatamente se los transfirió a los religiosos mercedarios que se encontraban en una apurada situación económica. Pero creo sinceramente que este don Diego Caballero no ejercitó en verdad el arte de la arquitectura ni fue ensamblador de retablos; a pesar de existir conciertos notariales de obra en los que aparece él como tal.

Conozco al menos cinco casos debidamente documentados en los que don Diego Caballero firmaba el concierto notarial y asumía todas las obligaciones contractuales; pero en los que ejecutaba la obra el mercedario fray Cristóbal Caballero. Curiosamente, todos estos conciertos se firmaron por los mismos años. Acaso, al no contar fray Cristóbal con licencia de sus superiores religiosos, ejercía el oficio de ensamblador algo clandestinamente; aunque se puede suponer que con el asentimiento implícito del comendador del convento. Cuando posteriormente obtiene la licencia del superior para estos menesteres, pudo dedicarse abiertamente al oficio y concertar obras en nombre propio.

Intervino don Diego en la firma del concierto notarial de 30 de abril de $1664{ }^{14}$ para hacer la cubierta de madera en el segundo claustro del convento de La Merced edificado por el alarife

14 A.G.N., escribano Juan Fernández Algaba, 1664, protocolo 458, folio 306v. 
Manuel de Escobar. El segundo concierto notarial de esta naturaleza atañe a un retablo: don Diego Caballero firmó el día 11 de septiembre de 1665 concierto notarial con Juan de Benavides, mayordomo de la cofradía de Nuestra Señora de los Remedios en la iglesia del convento de La Merced, para hacer un retablo nuevo sobre otro viejo retirado por el carpintero Pedro de Céspedes, además de otras tareas adjuntas, todo por el precio de 3.600 pesos de a ocho reales. ${ }^{15}$

El tercer caso da lugar a que los mayordomos de la cofradía de La Limpia Concepción en la iglesia de San Francisco manifestaran ingenuamente la ficción mantenida entre don Diego y fray Cristóbal. El ensamblador Asensio de Salas pretendió encargarse del retablo para esta cofradía, ya concertado con don Diego, y of reció para ello una apreciable rebaja en el precio total. Los mayordomos «veinticuatros» consultaron el problema con don Constantino de Vasconcelos, proyectista de la iglesia de San Francisco, y con fray Josefph Pizarro, religioso dominico que había ejercido el oficio de ensamblador antes de ingresar a la orden religiosa. Con cl dictamen favorable de estos peritos, los mayordomos decidieron firmar el concierto final con don Diego Caballero. Pues bien, el largo concierto notarial firmado el 19 de enero de 1666 por don Diego, en el que incorporan todos los autos del proceso, y los acuerdos de los «veinticuatros», ${ }^{16}$ contiene esta explicación de lo actuado: «y lo tenían concertado (el retablo) puesto y armado en blanco con Diego Caballero hermano del dicho fray Cristóbal Caballero que es la persona que lo había de hacer en once mil pesos de a ocho reales sobre el retablo viejo que tiene la cofradía... y se obligaba el dicho Diego Caballero con su persona y bienes sin embargo de ser a cargo y cuidado y disposición del dicho padre fray Cristóbal Caballero la obra del dicho retablo».

El cuarto caso documentado viene a ser complemento del retablo anterior. Consiste en un concierto notarial firmado el 8 de marzo de 1668 entre el mismo Diego Caballero y los diputa-

15 A.G.N., escribano Juan Fernández Algaba, 1665, protocolo 450, folio 559.

16 A.G.N., escribano Juan Fernández Algaba, 1666, protocolo 456, folio 1.653. 
dos de la cofradía de La Concepción en la iglesia de San Francisco para hacer dos retablos pequeños: uno para San Bernardo y el otro para San José, los que se habían de poner en los nichos a los lados del retablo grande de La Concepción, por el precio de 2.300 pesos. ${ }^{17}$ Aunque este concierto notarial no menciona para nada el nombre de fray Cristóbal Caballero, creo que no cabe la menor duda de que siendo las mismas las personas concertantes -don Diego y los «veinticuatros» de la cofradía de La Concepción - se repetía de nuevo la misma ficción jurídica antes confesada para que fray Cristóbal ejecutara la obra, a pesar de no estar en condiciones canónicas para concertarla.

El quinto caso, enteramente similar a los anteriores, ocurrió con fecha 2 de agosto de 1669, en que don Diego firmaba el concierto notarial para hacer el retablo en blanco para la capilla de Nuestra Señora de Gracia en la iglesia del convento de San Agustín; aunque aquí se indica que este retablo se haría «conforme a la traza y modo de la planta que ha dado el padre maestro fray Cristóbal Caballero del Orden de Nuestra Señora de La Merced». ${ }^{18}$

A mi modo de entender, se trataba de una ficción jurídica inventada para soslayar la dificultad de que, siendo fray Cristóbal Caballero religioso, no podía comprometer bienes propios para garantizar el cumplimiento del concierto notarial o para asegurar los pesos que le adelantaban para ejecutar las obras, según era costumbre en los conciertos notariales de la época; además de

17 A.G.N., escribano Fabián Fernández, 1668, protocolo 548, folio 1.601v.

18 A.G.N., escribano Martín Alonso Palacios, 1669, protocolo 1.375, folio 1.480. Mencionemos también otros pequeños trabajos ejecutados por fray Cristóbal en aquellos años: el 9 de octubre de 1663 otorgó carta de pago a fray Marcelo de Valenzuela por los trabajos ejecutados en el túmulo de Catalina de Afrazgo: A.G.N., escribano Nicolás García, 1663, protocolo 701, folio 1.491. El 14 de diciembre de 1665 otorgó carta de pago al administrador de la cofradía de la Concepción en San Francisco por 650 pesos del trabajo de armar el retablo viejo y una pintura: A.G.N., escribano Fabián Fernández, 1665, protocolo 544, folio 1.896. El 4 de julio de 1668 firmó concierto con don Bernardo de Novoa para una tarea desconocida, pues no se anotó el concierto, sino sólo el encabezamiento, y las firmas: A.G.N., escribano Joseph del Corro, 1668, protocolo 396, folio 26. Lo mismo sucedió hacia 1689: A.G.N., escribano Pablo González Romo, 1688-1689, protocolo 812 , sin numeración de folios. 
que posiblemente en alguna ocasión no contaba con la licencia de sus superiores religiosos para dedicarse a tales menesteres. El remedio más sencillo consistía en hacer aparecer a su hermano Diego como firmante del concierto, y como responsable de todas las obligaciones económicas inherentes al mismo; pero siendo fray Cristóbal quien ejecutaba y había diseñado la traza del retablo concertado. En otras ocasiones, en que pudo contar con la licencia del padre comendador del convento para hacer retablos, como es el caso del retablo mayor para la iglesia del monasterio de La Santísima Trinidad, fray Cristóbal se limita a presentar a su hermano Diego como fiador y llano pagador exigido por las cláusulas notariales de la época.

Esta relación entre los dos hermanos, Cristóbal y Diego, tiene todas las apariencias de haber sido muy íntima y solidaria, pues los numerosos conciertos notariales otorgados por don Diego Caballero aparecen firmados con su nombre y apellidos, pero escritos con la caligrafía inconfundible de la firma de fray Cristóbal Caballero. Esta curiosa suplantación de firmas se constata patentemente en las firmas del concierto notarial con la abadesa del monasterio de La Santísima Trinidad, donde firman los dos hermanos: fray Cristóbal lo hace con nombre y apellido completo en cuanto principal otorgante de la escritura; y don Diego lo hace como su fiador, pero poniendo solamente sus iniciales D. C. Ahora bien, esta inicial del apellido de don Diego es exactamente igual a la de la firma del mercedario. Si en los documentos firmados por don Diego Caballero se quitara el nombre de Diego y se pusiera en su lugar el de Cristóbal, resultaría la firma auténtica y completa de fray Cristóbal Caballero escrita con la misma letra tan bella y clara, rubricada con los mismos garabatos con que lo hacía habitualmente el mercedario.

El concierto notarial camuflado para la ejecución del retablo de Nuestra Señora de Gracia en San Agustín no aportal ningún detalle ni descripción de la obra; solamente menciona el autor de la traza y el precio en que se concertaba, que era de 4.700 pesos, además de entregarle el retablo viejo. 


\section{2.-Ei. monumento en honor de Carlos II}

Existe un documento gráfico de extraordinario valor para conocer las tendencias estilísticas prevalecientes hacia mediados del siglo XVII en Lima, así como para evaluar la obra de fray Cristóbal Caballero. Se trata del grabado que representa el monumento levantado por la Ciudad de los Reyes del Perú en honor del rey Carlos II, con fecha 17 de octubre de 1666, que aparece claramente atribuido a nuestro religioso mercedario. Ha sido publicado por Humberto Rodríguez Camilloni. ${ }^{19}$ Constituye este monumento una semejanza de retablo a la que sólo le faltaría para ser tal que le incorporaran la mesa del altar y que colocaran en él las imágenes y el sagrario. Consta de dos cuerpos de columnas y un cuerpecillo de pilastras coronado con una cupulilla con adornos renacentistas. Las columnas del segundo cuerpo muestran el primer tercio «melcochado» en estrías enrolladas en espiral; y las columnas del primer cuerpo son un perfecto anticipo de las que se tallarían pocos años después en la portada principal de la iglesia del convento de San Francisco de Lima. Este grabado demuestra que no es necesario acudir a ese enigmático e inexistente Carlos Pavía, a quien Vargas Ugarte atribuyó el retablo de La Inmaculada en la catedral de Lima, para explicar la portada de San Francisco, como lo hace Wethey; ${ }^{20}$ pues siguiendo el mismo criterio, deberíamos atribuir la paternidad de la portada franciscana a fray Cristóbal Caballero, cosa que no es cierta. Es cierto que el estilo de las columnas del monumento y del retablo catedralicio concuerdan con las de la portada franciscana. En cuanto al retablo de La Concepción en la catedral, he descubierto y publicado el concierto notarial firmado por el ensamblador Asensio de Salas

19 Rodríguez Camilloni, H.: El conjunto monumental de San Francisco de Lima en los siglos XVII y XVIII, en *Boletín del Centro de Investigaciones Históricas y Estéticas», núm. 14, Universidad de Caracas, 1972, págs. 31-60, véase pág. 49.

20 Wethey, H. E.: Colonial architecture and sculpture in Perú, Harvard, 1949, pág. 222. 
para labrarlo; ${ }^{21}$ es un retablo de 1654 . Fray Cristóbal Caballero estuvo muy vinculado al ensamblador Asensio de Salas, hasta el punto de que continuó algunas obras dejadas inconclusas por éste a su muerte.

Tiene especial valor la forma volumétrica plasmada en este monumento pues la calle central de los tres cuerpos aparece situada en un plano más adelantada que los intercolumnios laterales del primer cuerpo; y esta calle central conforma una especie de planta rectangular coronada en los dos primeros cuerpos por arcos apoyados sobre los soportes de columnas. Resalta a primera vista que los arcos frontales más interiores en ambos cuerpos son más pequeños y están colocados a menor altura que los arcos frontales delanteros; lo cual aparece claramente por la menor altura de los soportes más interiores respecto de los soportes del primer plano.

Pudiera pensarse que ello no es más que un efecto de perspectiva arbitrado por el dibujante del grabado. Tenemos sin embargo, suficiente motivo para suponer que este efecto de perspectiva no fue un recurso del grabador, sino la conformación real y objetiva del monumento dada por el mismo Caballero; de tal manera que el dibujante no hizo otra cosa que representar con fidelidad lo que la obra expresaba. En efecto, en el concierto notarial de obra para el retablo de la Santísima Trinidad, el mismo fray Cristóbal Caballero especifica que la caja en la que ha de ponerse el Sagrario también se cubriría con cuatro arcos, de los cuales el interior en la testera había de ser menor que el paralelo de enfrente en la parte delantera. El arquitecto mercedario objetivaba la perspectiva volumétrica, no dejándola librada a una impresión subjetiva del contemplador, sino plasmándola mediante una reducción real de la altura de los elementos colocados en el segundo plano; y también reduciendo el tamaño de los mismos. Si tratamos de expličar qué razones pudo tener fray Cristóbal Caballero para objetivar así el efecto de perspectiva, en lugar de

¿1 San Cristóbal Sebastián, A.: El retablo de La Concepción en La Catedral de Lima, en «Historia y Cultura. Revista del Museo Nacional de Historia», número 15, Lima, 1982, págs. 91-108. 
dejar que cada espectador lo formase en su propia percepción subjetiva, acaso pueda ello derivarse de que la formación del efecto de perspectiva requiere que interceda una cierta distancia entre el espectador y el objeto contemplado; y que cuando tal distancia no existe, tampoco se puede producir la deformación de perspectiva en la visión del objeto. Puesto que las obras arquitectónicals de fray Cristóbal Caballero sólo se contemplaban desde corta distancia, él prefirió plasmar objetivamente el efecto de perspectiva en las mismas, antes que privar de tal efecto a sus contempladores. En cierta manera, este arquitecto mercedario diseñaba sus trabajos en perspectiva al modo como los pintores italianos del Renacimiento acentuaron la proyección de la perspectiva en sus cuadros; claro que hay que salvar siempre la distinción que intercede entre un lienzo plano, en el que se representa la perspectiva, y una construcción arquitectónica tridimensional que incorpora la perspectivil objetivamente.

Cada trilogía de columnas en el monumento a Ciarlos II expresa igualmente un planteamiento volumétrico, pues lia columna central de mayor altura y grosor que las dos laterales, antecede a estas menores que están más retrasadas.. Este efecto volumétrico aparece también en la portada principal de San Francisco de Lima, y sabemos que lo usaba Asensio de Salas en sus retablos, como aparece claramente en el de la Limpia Concepción de la catechal de Lima.

Resalta llamativamente la diferencia de altura en los soportes; del primer cuerpo, pues distinguimos allí hasta cuatro niveles de altura en los fustes de las columnas; lo cual a su vez origina la superposición de uno, dos, tres, y hasta cuatro cubos de entablamento sobre los respectivos capiteles corintios de las columnas.

Estos trabajos muestran que en la década de 1660 gozaba fray Cristóbal Caballero de reconocido prestigio profesional en la Ciudad de los Reyes del Perú. El suntuoso púlpito tallado por el ensamblador Diego Agnes para la catedral de Lima, tan ponderado en el lenguaje barroco del contador Echave y Assú, era objeto de un contencioso reclamo entre el autor y el cabildo metropolitano. Aunque parece ser que los canónigos limeños hicieron oídos 
sordos a las reiteradas reclamaciones de pagos adicionales formuladas por el pretencioso don Diego Agnes, ellos no encontraron otra evasiva más adecuada que la de encomendar la tasación del púlpito en controversia a algunos peritos, entre los cuales se designó a fray Cristóbal Caballero por delegación dada el día 24 de septiembre de $1669 .^{22}$

\section{3.-LA PORTADA DE LA IGLESIA DEL monasterio de Santa Catalina}

El año de 1671 , a consecuencia de la muerte del ensimblador Asensio de Salas, acaecida en 1669, sobrevino sobre fray Cristóbal Caballero una cierta acumulación de trabajos importantes en arquitectura de obra y de madera. He localizado la documentación notarial referente a los retablos para la iglesia del monasterio de Santa Catalina de Sena, la de la portada de la misma iglesia y la del grandioso retablo para el altar mayor del monasterio de la Santísima Trinidad que Harth-Terré sólo conocía por algunos registros de pago.

Las relaciones profesionales entre el mercedario fray Cristóbal Caballero y el monasterio de Santa Catalina se reforzaban por sus vínculos familiares, pues sus dos sobrinas hijas de don Diego profesaban como monjas de velo negro en el mismo monasterio. Por escritura de 12 de octubre de 1679, la monja Isabel Caballero renunciaba a su legítima en favor de su padre don Diego, reservando 6.000 pesos a favor de su hermana si se hacía monja; pues de lo contrario fundaría una capellanía a favor de su hermano Diego Caballero Castro, que era sacerdote. ${ }^{23}$ Aunque según el testamento de don Diego también la otra hermana profesó como monja, de todos modos doña Isabel fundó la capellanía a favor de su hermano Diego por escritura de 22 de diciembre de $1684 .{ }^{24}$

22 Archivo Arzobispal de Lima, Libro de Fábrica de la Catedral, legajo 4. 16:33-1677; papeles sueltos de esta reclamación al cabildo.

23 A.G.N., escribano Pedro Pérez Landero, 1679, protocolo 1.471, folio 1.236.

24 Ibidem, 1684, protocolo 1.481, folio 1.191. 
Una primera tarea revertida sobre fray Cristóbal Caballero consistió en terminar los trabajos concertados por Asensio de Salas con el monasterio de Santa Catalina por concierto notarial de 27 de mayo de 1669 por la fabulosa cantidad de 32.670 pesos de a ocho reales. ${ }^{25} \mathrm{La}$ muerte de Salas antes del día 16 de agosto de este año de 1669, le impidió cumplir con lo concertado; para lo cual le había adelantado el monasterio una fuerte cantidad. Gran parte de las tareas incumplidas fueron terminadas por fray Cristóbal Caballero, pues el día 14 de mayo de 1673 otorgó carta de pago a la abadesa del monasterio de Santa Catalina por ${ }^{4}$ valor de 10.092 pesos correspondientes a numerosos trabajos de los encomendados anteriormente a Asensio de Salas, además de otros que le competían a él mismo; ${ }^{26}$ y meses más tarde, el 12 de septiembre del mismo año de 1673 , otorgó otra carta de pago adicional por «dos cuadros para dos ángeles, tres coronaciones y dos arbotantes para la iglesia», lo que importaba 300 pesos. ${ }^{27}$

Alterando ahora el orden cronológico, mencionamos entre los encargos recibidos por fray Cristóbal Caballero en 1671 los dos retablos colaterales para la iglesia del monasterio de Santa Catalina, dedicados el uno a Santo Domingo y el otro a la Santa Patrona de la iglesia. Este concierto notarial firmado el día 8 de junio de 1671 no aporta otros detalles acerca de los retablos más que el de su precio de 3.000 pesos por ambos en conjunto; lo que indica que no llevarían mucha labor de obra. ${ }^{28}$ Anteriormente, el día 16 de septiembre de 1670 había concertado fray Cristóbal Caballero un retablo de ocho varas junto a la reja del coro en Santa Catalina por valor de 1.700 pesos de a ocho reales. ${ }^{29}$

La primera obra importante de 1671 consistió en labrar la

25 Copia de este concierto en el Archivo Arzobispal de Lima, Monasterio de Santa Catalina, legajo 4,1660-1669. Se inscribió ante Tomás Ortiz de rastro, pero la copia es de Marcelo Antonio de Figueroa.

26 A.G.N., escribano Martín Alonso Palacios, 1673, protocolo 1.383, folio 358.

27 Ibídem, protocolo 1.384, folio 1.745 .

28 A.G.N., escribano Marcelo Antonio de Figueroa, 1671, protocolo 668, folio 1.542. El día 17 de julio de 1670 concertó otro retablo para el pueblo de San Pedro de Casta: A.G.N., escribano Bartolomé Maldonado, 1668-1671, protocolo 1.055. folio 703. folio 2.263 .

29 A.G.N., escribano Marcelo Antonio de Figueroa, 1670, protocolo 666. 
portada para la iglesia del mismo monasterio de Santa Catalina concertada el 8 de abril de 1671 según el concierto que se incluye como Anexo Documental. ${ }^{30}$ Este concierto demuestra la versatilidad del artífice mercedario, pues le vemos variar en el mismo año desde la tarea de ensamblador y la talla en madera a la de construcción de obra firme. Pero no sólo aportó la planta y traza para esa portada, sino que además se concertaba como constructor de ella, obligándose «de hacer la dicha portada de albañilería y cantería y para ello se han de sacar los cimientos necesarios desde lo firme y sobre ellos se han de plantar los pedestales de cantería labrada de Arica». Cualquiera podría suponer que este fraile mercedario se entrometía con audaz improvisación en actividades que no eran de su competencia, sorprendiendo la buena fe de unas simples monjas. Sin embargo, nada más lejos de ello, pues la licencia que le concedió el padre comendador de La Merced para hacer esta obra afirma que «tenemos hecho nombramiento de Maestro mayor de todas las obras de este dicho Convento al padre predicador fray Cristóbal Caballero religioso profeso y sacerdote de nuestra sagrada Religión atento a la pericia que tiene en su arte». Asimismo, en la licencia que el mismo comendador de La Merced le otorgaba el día 1 de octubre del mismo año de 1671 para que pudiera hacer el retablo del monasterio de la Santísima Trinidad, le denominaba «Maestro mayor de todas las obras de esta Provincia». Desde luego, se trataba del título de maestro mayor para uso interno de la Orden Mercedaria; pero no por ello debe infravalorarse la competencia de fray Cristóbal Caballero en los menesteres del arte de la arquitectura. Debido a ello, llegará a finales del siglo XVII a asumir el cargo oficial de maestro mayor de fábricas reales que por su muerte había dejado vacante el dominico fray Diego Maroto. Si bien, no tendría fray Cristóbal a fines de 1671 labor muy comprometida ni transcendente en su convento mercedario, en cambio a finales del siglo XVII intervino documentalmente en tareas como la de establecer las «condiciones» para los reparos de la muralla de Lima cuyo concierto

30 Ibídem, 1671. protocolo 667, folio 832. 
notarial se conserva y se transcribe como Anexo. ${ }^{31}$ No debemos olvidar esta «pericia en su arte» que le atribuía su propio superior religioso; ya que el terremoto de 1687 le proporcionaría la gran oportunidad para ejercitarla en la restauración de la jolesia del convento de La Merced de Lima, donde él vivía.

La portada de la iglesia de Santa Catalina no llevaba columnas, sino pilastras y traspilastras; pero su construcción resaltaba en gran relieve respecto del muro de fondo al que se anteponía. El arquitecto mercedario plasmó un volumen desigual para los diversos cuerpos de la portada, pues el plano de los cuerpos superiores quedaba más retrasado que el plano externo del cuerpo inmediatamente inferior; $y$ puesto que las pilastras del segundo cuerpo más retraído que el primero sobresalían de la pared de fondo tres cuartas, los pedestales labrados en piedra de Arica, «que no es salitrosa porque no se coma el ladrillo», sobresaldrían en gran manera del muro de fondo. Son importantes las palabras de fray Cristóbal Caballero en el mismo concierto: «Con declaración que al plantar las bases de los pedestales se les han de dar el relieve necesario para que habiendo disminuido hacia adentro segundo y tercer cuerpo se quede el relieve necesario de la pared para afuera a los algotantes y resaltos de las traspilastras de suerte que por las cañas de las pilastras del segundo cuerpo tenga tres cuartas de relieve antes más que menos». Además de la conveniente incorporación de la portada con el muro de la pared, se planeaba deliberadamente este desnivel entre los cuerpos «para que quede seguro de temblores todo bien acondicionado». Los pedestales actuales de la portada catalina, que sin duda son los que plantó fray Cristóbal Caballero, muestran todavía el gran rclieve y volumen otorgado a la obra de esta portada. El desnivel entre el muro de fondo y los diferentes planos en saliente de la portada se salvaban mediante ese cxpediente tan limeño de los resaltos de las traspilastras; es decir, mediante los planos quebrados en escalonamiento descendente hasta el interior, al modo como se observa en la portada lateral de la iglesia de San Fran-

31 A.G.N., escribano Diego Fernández Montano, 1698, pro!ocolo 502, folio 666v. 
cisco, obra del alarife Manuel de Escobar y posterior a la portada catalina.

Aún insiste Caballero en otro detalle que aumenta el gran volumen conferido a esta portada: las pilastras del primer cuerpo sobresaldrían lo necesario «para que las impostas del arco principal se incluyan como demuestra la traza»; o sea, para que esas impostas quedaran en un plano más retrasado que las pilastras, y pudieran continuarse lateralmente en toda la portada por detrás de los ejes de las pilastras.

La portada de Santa Catalina se ornamentaba con los adornos usuales hacia mediados del siglo XVII; sólo que no estarían tallados en piedra sino modelados en «barro cocido de ollería», a saber, «todas las tallas de serafines, marioletas, y fruteros y capiteles y los santos que se han de poner en la dicha portada que irán declarados en esta escritura así mismo han de ser de barro cocido».

Consta que fray Cristóbal ejecutó puntualmente la portada de las monjas catalinas, pues su precio de 3.200 pesos aparece consignado entre los diversos trabajos a que se refiere la carta de pago del día 4 de 1 mayo de 1673 otorgada por ante el escribano Alonso Martín Palacios.

\section{4.-El retablo de la Santísima Trinidad Y OTROS TRABAJOS}

La otra obra importante encomendada en 1671 a fray Cristóbal Caballero y aceptada contractualmente por él, mediante licencia expresa del comendador del convento de La Merced, fue el gran retablo para el altar mayor de la iglesia del monasterio de monjas cistercienses de la Santísima Trinidad. En esto, como en otras cosas, fue Harth-Terré quien proporcionó la primera información acerca del mencionado retablo; pero se basaba únicamente en el Libro de Cuentas del síndico del monasterio conservado en el Archivo Arzobispal de Lima; esta fuente documental no informa más que acerca de los pagos efectuados a fray Cristóbal Caballero, pero no dice absolutamente nada acerca de la obra arquitectónica 
del retablo. Posteriormente, he descubierto el concierto notarial firmado por la abadesa del monasterio y fray Cristóbal Caballero el día 1 de octubre de $1671 ;{ }^{32}$ y este documento permite reconstruir la historia completa del retablo, así como describir su conformación arquitectónica.

Tuvo el retablo de la Santísima Trinidad una historia harto irregular hasta que llegó a ser colocado definitivamente en su lugar; pero parece que alcanzó efímera existencia, porque el terremoto de 1687 arruinó la iglesia y el convento, y posiblemente destruiría el retablo. De todos modos, este retablo no duraría más allá del terremoto de 1746. Concertó la escritura fray Cristóbal con la abadesa del monasterio doña Marcela de Aguilar, previa licencia escrita dada por el padre comendador de La Merced e inserta en el texto del concierto notarial; aunque también aparece antepuesta al mismo concierto en su texto original. 'Tratando de este retablo, cuyo concierto no conocía, prefirió Harth-Terré calificar a Caballero como «maestro escultor»; pero en el texto del concierto registrado ante Tomás de Quesada figura como «maestro arquitecto»; y en verdad, sin dejar de ser lo primero, se ejercitó en este retablo cumplidamente como artífice de arquitectura en madera.

En el mismo concierto se establecían los plazos para la ejècución del retablo: el día 20 de agosto estaría colocado el primer cuerpo en blanco; el segundo cuerpo a los seis meses siguientes; y el tercero y lo restante en otros seis meses; finalizándose el día 20 de agosto de 1673, festividad de San Bernardo, fundador de la Orden Cisterciense. No por culpa de fray Cristóbal Caballero, sino por incumplimiento en los pagos por parte del monasterio, se retrasó todavía otros tres años la terminación del retablo y su colocación. Las cartas de pago otorgadas por fray Cristóbal Caballero se sucedieron desbordando ampliamente los plazos señalados en el concierto: el 6 de diciembre de 1671 otorgó carta de pago a cuenta del retablo ${ }^{33}$ por 4.300 pesos. Casi dos años más tarde, el 30 de noviembre de 1673 , otorgaba otra carta de pago por

32 A.G.N., escribano Tomás de Quesada, 1671-1672, protocolo 1571, folio 190.

33 Ibídem, folio $365 \mathrm{v}$. 
873 pesos a cuenta del retablo. ${ }^{34} \mathrm{El} 11$ de mayo de 1674 otorgó nueva carta de pago consolidando el valor de los materiales recibidos y de los pagos adelantados en la cantidad global de 10.500 pesos «por el entero de los dos cuerpos del retablo»; ${ }^{35} \mathrm{y}$ el mismo día adjunta seguidamente otra carta de pago por 1.127 pesos «por cuenta de tres mil y quinientos que el dicho monasterio le resta debiendo para el entero del tercer cuerpo del retablo». ${ }^{36} \mathrm{Y}$ todavía en marzo de 1676 seguía reclamando fray Cristóbal Caballero que le pagaran el resto de la deuda y afirmaba que «con todo proseguí en la obra hasta ponerla de dos cuerpos y porque habiendo acabado el tercero no se me ha dado el resto que son dos mil y cuatrocientos pesos he suspendido el ponerlo hasta que esté satisfecho y porque ha más tiempo de dos años que le tengo acabado y con el tiempo puede tener menos valor...». ${ }^{37}$ Por fin llegaron a un acuerdo honorable para el pago de la deuda pendiente y se pudo colocar el retablo, aunque con un retraso notable con relación a los plazos establecidos en el concierto de obra.

De la lectura del concierto notarial se desprende que Asensio de Salas apenas había ejecutado antes de su muerte otra cosa que «el sagrario, bancos, columnas y tarjas sueltas»; todo lo cual le entregaron a Caballero como parte del pago total de la obra. Pero, al asumirlo, el arquitecto mercedario rehizo completamente la planta y traza inicial; hasta el punto de que el retablo resultá siendo obra suya en cuanto al diseño 'y ejecución, exceptuando sólo ese Sagrario labrado por Salas. Las prolijas y abundantes «condiciones» concertadas por Caballero atestiguan que no se limitó a terminar una obra planeada y comenzada por otro ensamblador, aunque éste fuera del prestigio de Asensio de Salas, como ha sostenido el arquitecto-historiador Harth-Terré.

Comenzó fray Cristóbal Caballero por acomodar la proporción de los tres cuerpos del retablo, pues el segundo en la traza de Salas resultaba desproporcionado en relación a los otros dos:

34 Ibídem, 1673, protocolo 1.573 , folio 776 .

35 Ibídem, 1674, protocolo 1.574, folio 291.

36 Ibídem, folios 291r.-291v.

37 Archivo Arzobispal de Lima, Monasterio de La Santísima Trinidad. lega jo 7, 1674-1679, papel sin numeración. 
«de segundo cuerpo el cual ha de crecer respecto del todo, porque el que está hace poca consonancia a la máquina del todo además de estar alto y disminuirla». El remedio para agrandar el segundo cuerpo consistió en rebajar tres gradas del pavimento, para que este espacio lo ganara en altura el retablo, especialmente en el segundo cuerpo. El maestro Asensio de Salas acostumbraba en sus trabajos formar bloques de a tres columnas en cada uno; una de ellas principal y a los dos lados otras dos más pequeñas y retrasadas; pero en este retablo había reducido las columnas laterales de los bloques a sólo cuartos de columna adheridos a los lados de la gran traspilastra de la columna principal. Buscaba así la apariencia efectista, pero reduciendo el costo en madera y trabajo: yal que no tallaba el fuste completo de las columnas laterales. Por el contrario, Caballero prefirió la autenticidad de poner columnas laterales enteras en el primero y segundo cuerpo; aunque para ello debió de modificar la traspilastra de la columna principal. Modificó igualmente la conformación ornamental de las calles liaterales del retablo en el primer cuerpo, en la parte superior de los nichos: "y acompañar los segundos cuerpecillos que rompen la cornisa principal del primer cuerpo y esos tablerillos se aminoren y lleven frontispicios como lo es el del medio».

Para interpretar posteriormente la portada de La Merced, nos importa ahora en gran manera destacar algunas aportaciones estilísticas peculiares de fray Cristóbal Caballero en este retablo cisterciense. Para alojar la gran pieza del Sagrario dejada por Asensio de Salas formó en el primer cuerpo una especie de baldacquino o cobertura coronada por una bovedilla «vaída ovalada»: la que sustentaba en cuatro arcos. Pues bien, en este retablo reiteró fray Cristóbal Caballero el mismo efecto de objetivar la perspectiva, ya aplicado anteriormente en el monumento a Carlos II: «y el arco de la espalda ha de ser menor que el de afuera para que vaya siempre manifiesto a la vista los lados y lo cubierto que va sobre los cuatro arcos dos pequeños a los lados y uno en la testera menor que el de fuera».

Añade en el entablamiento del Sagrario una especie de abrazaderas superpuestas que él denomina «cortezas»: «que abracen 
el alquitrabe y miembros de la cornisa y en ellas las mensulillas que hoy tienen y lo mismo en los del segundo cuerpo». Y lo rejtera más adelante: «Item es condición que los bancos del Sagrario se han de enriquecer con algunas cortezas que abracen las molduras así de los pedestales como de los recuadros». Este detalle tan original de Caballero tiene especial significación, como se verá al analizar la portada de La Merced.

En el tercer cuerpo del monumento a Carlos II no colocaba columnas, sino pilastras adornadas con «fruteros». Para este retablo de la Santísima Trinidad varía la ornamentación; pues añade lo siguiente: «Item condición que en las pilastras del tercer cuerpo a donde están las frutas se han de poner unas mensulillas o cargadores que sustenten la arquitectura de arriba». Este detalle es de gran importancia, porque demuestra que desde antes de la portada lateral de la iglesia de San Francisco, se empleaban en la arquitectura limeña las pilastras con modillones en lo alto a modo del capitel; que constituyen un elemento arquitectónico específico de la escuela barroca limeña.

Finalmente, propone adornar las jambas de los nichos de las calles laterales con unas molduras talladas del siguiente modo: «Y los muros de los lados de los nichos por encima se han de guarnecer con recuadrillos de molduras talladas o tarjillas largas y angostas».

Otras modificaciones propuestas por Caballero confieren al retablo una estructura y apariencia muy distinta de la que inicialmente señalaba Asensio de Salas. No se trataba, pues, simplemente de terminar una obra inconclusa; sino de ensamblar una planta y traza diseñadas por fray Cristóbal Caballero en sustitución de las de Asensio de Salas.

Todas estas obras habían consolidado el prestigio profesional de este ensamblador y alarife mercedario; y naturalmente le ganaron nuevos encargos. Con fecha 18 de agosto de 1674 otorgaba carta de pago por valor de 1.500 pesos de a ocho reales correst pondiente a la hechura del arco en la calle de Mercaderes para recibir al nuevo virrey conde de Castellar, según el encargo que 
le había hecho el Tribunal del Consulado. ${ }^{38}$ Lamentablemente, no se conocen detalles de esta obra.

Mayor importancia reviste, tanto por las dimensiones como por su precio, el retablo concertado con los señores curas de la iglesia del Sagrario en la metropolitana de Lima, para hacer el retablo del altar mayor. El concierto se firmó con fecha 21 de enero de 1681 por el valor de 10.000 pesos. ${ }^{39}$ No se incluyen en el concierto notarial otros detalles del retablo que sus dimensiones que, a la letra, dicen lo siguiente: «Veinte y dos varas de largo (acaso deba decir de alto) y de ancho doce más o menos»; pues para lo demás se remite a la planta y traza presentada por fray Cristóbal Caballero. Cada uno de los tres cuerpos se entallaría en el plazo de ocho meses; a no ser que le entregaran todo el precio, en cuyo caso lo terminaría en un año. Firmó este concierto notarial previa licencia dada por el padre comendador del convento de La Merced, en la que se denomina a Caballero como «maestro mayor de obras de nuestro convento». Para esta fecha de 1681, ese título sería pura denominación sin efectividad; pues sin duda se vio obligado nuestro alarife a reparar los daños sufridos en la iglesia y convento mercedario por el fuerte temblor de tierra de 1678. Además de comprometer para hacer el retablo sus bienes, entre ellos «una casa y todos sus esclavos», presenta como fiadores del dinero recibido y del cumplimiento del concierto a Miguel de Garay, que era alarife con título de capitán, y a su hermano don Diego Caballero. Al final de esta escritura estampó esta vez su firma completa el fiador don Diego; y se observa en ella con toda claridad que está escrita con la misma caligrafía y rúbrica que la de fray Cristóbal, pues ambas firmas están anotadas a escasa distancia una de la otra.

Poco tiempo después de concertar el retablo para la iglesia del Sagrario de la catedral, se ejecutaron en el convento de La Mer-

38 A.G.N., escribano Alonso Martín Palacios, 1674, protocolo 1.387, folio 1.366.

39 A.G.N., escribano Pedro Pérez Landero, 1681, protocolo 1.474, folio 195. Con fecha 6 de febrero de 1691 otorgó Caballero a Antonio Guillén carta de pago por 114 pesos que éste le adeudaba por cierto trabajo desconocido; y se los pagaba porque «le tenía ejecutado» el trabajo: A.G.N., escribano Pedro Arias de Ron, 1690-1691, protocolo 162, folio 26. 
ced donde vivía Caballero las obras del nuevo noviciado y unas celdas del mismo; 'y consta documentalmente que para ellas ejercitó fray Cristóbal Caballero su oficio de «maestro mayor de obras de nuestro convento». En efecto, con fecha 6 de junio de 1679 firmaron los padres provincial y comendador de La Merced el concicrto de obra con el maestro de albañil Francisco Javier Domínguez. ${ }^{40}$ Se incluye como Anexo documental.

Ciertamente, este concierto no contiene detalles de la arquitectura del nuevo noviciado mercedario, ya que tales obras se habrían de realizar «en la forma y según que se contiene en la planta y modelo que está hecho en un papel y firmado de todos los otorgantes y de mí el presente escribano sin exceder de él en cosa alguna». Ahora bien, el concierto señala implícitamente que el autor de la tal planta y modelo habría sido fray Cristóbal Caballero; pues también actuaba como director técnico de los trabajos, ya que el maestro Domínguez quedaba obligado a hacer la obra «bien y cumplidamente y a satisfacción del padre fray Cristóbal Caballero religioso del mismo Orden». Una fórmula similar a esta aparecía frecuentemente en los conciertos notariales de obra cuya planta y dirección habían corrido a cargo del dominico fray Diego Maroto. Por ello, no interesa ahora esta edificación en sí misma, cuanto el hecho de que fray Cristóbal Caballero planeaba y dirigía todas las obras que por aquellos años se ejecutaban en el convento de La Merced de Lima. Nada autoriza, pues, a suponer que en otros casos de mayor necesidad dejarían los mercedarios de utilizar la pericia de fray Cristóbal como maestro mayor de obras, sobre todo si las tareas eran grandes y los recursos económicos estaban escasos; y tampoco cabe suponer que fray Cristóbal, religioso que vivía en el mismo convento, dejaría de acudir prestamente como buen religioso en ayuda de su comunidad y convento.

Otra situación similar y conjunta con ella se produjo al mes siguiente de celebrado el anterior concierto notarial de obra, al acumularse otro nuevo concierto por el cual, con fecha 18 de julio de 1679, el mismo maestro albañil Francisco Javier Domínguez

40 A.G.N., escribano Nicolás García, 1679, protocolo 720, folio 253. 
se comprometía a levantar la planta alta del segundo claustro mercedario iniciado en 1662 por el alarife Manuel de Escobar. ${ }^{41}$

A partir de mediados del año de 1685 , las actividades arquitectónicas de fray Cristóbal Caballero quedarían interrumpidas por un período no inferior a tres años. En el capítulo provincial de la Orden de La Merced iniciado el 21 de mayo de 1685 fue elegido comendador del convento de La Merced del puerto del Callao; ${ }^{42}$ cargo en el que estaba obligado a permanecer hasta mayo de 1688. Es cierto que el 25 de mayo de 1688 otorgaba carta de pago por 3.125 pesos al capitán don Agustín de Castro, mayordomo de la cofradía del Santísimo Sacramento en la metropolitana de Lima por la hechura de un tabernáculo grande en la capilla del Sagrario del altar mayor y por cuatro hacheros que hizo; ${ }^{4.3}$ pero no podemos determinar si se trataba de cobrar una deuda atrasada; o si se trataba de un encargo nuevo ejecutado durante el tiempo de su permanencia en el cargo de comendador del Callao. Desde luego, este cargo de comendador en el puerto del Callao le inhibía de otras ocupaciones, como era la de administrador de la hacienda denominada de Surquillo, propiedad del convento de La Merced de Lima; motivo por el cual tuvo que arrendarla al alférez Cristóbal García de Paredes con la licencia de sus superiores. ${ }^{44}$

Al término de su «encomienda» en el convento de La Merced del Callao, se reintegró al convento grande de San Miguel de Lima. En efecto, figura entre los religiosos con voz y voto en los capítulos provinciales de 1688, 1691, 1694, 1697, 1700; pero en el que se inició el 24 de agosto de 1703 aparece su nombre entre los religiosos fallecidos desde el anterior capítulo provinfolio 143

41 A.G.N., escribano Francisco Pérez de Soto, 1679-1680, protocolo 1.527,

42 Archivo del Convento de La Merced de Lima, Libro de Provincia. 1685. 1720, folio $6 r$.

43 A.G.N., escribano Francisco Sánchez Becerra, 1688, protocolo 1.699, folio 233.

44 A.G.N., escribano Pedro Pérez de Cavañas, 1685-1688, protocolo 1.422, folio 389. El concierto tiene fecha de 30 de ener• de 1687. Se reiteró ese arrendamiento por otro concierto de 28 de abril de 1688. 
cial. ${ }^{45}$ Anteriormente, con fecha 24 de noviembre de 1684 , le confirieron el grado académico de Presentado, según patente firmada en Madrid por el padre general de la Orden de La Merced a 30 de mayo de 1684, y ratificado en Lima por acuerdo del virrey duque de la Palata el día 11 de julio de $1689 .{ }^{46}$

\section{5.-Tas cubiertas del claustro de Santa Catalina}

La participación de fray Cristóbal Caballero en la reconstrucción del claustro del monasterio de Santa Catalina después del terremoto de 1678 es otro de los temas deformados por una información incompleta y mal leída. Había visto Harth-Terré algunos papeles en los legajos del monasterio de Santa Catalina conservados en el Archivo Arzobispal; y sin hacer un estudio completo de ellos, y también sin conocer la historia de la edificación de este claustro catalino, escribió a la ligera estas palabras: «fray Cristóbal Caballero, en el año de 1678, tuvo a su cargo la ejecución del claustro principal del monasterio de Santa Catalina de Sena en esta ciudad». ${ }^{47} \mathrm{~A}$ partir de esta información, y sin consultar los documentos, otros historiadores han proseguido considerando a fray Cristóbal Caballero como constructor del claustro de las dominicas catalinas. ${ }^{48}$

En realidad, el claustro existía desde mediados del siglo XVII, cuando lo construyó el maestro Juan de Mansilla, según consta por la documentación que he descubierto en el Archivo General de la Nación de Lima. Este claustro tenía cubiertas de bóvedas de arista en sus corredores, labradas con cal y ladrillo, pero resulta que estas bóvedas se hundieron en el terremoto de 1678; no así los pilares y las arquerías, salvo dos o tres que tuvieron que y $154 \mathrm{v}$.

45 Archivo del convento de La Merced, Libro de Provincia. folios 55r., 93r.

46 Ibidem, fol. $47 \mathrm{v} .-48 \mathrm{r}$.

47 Harth-Terré, Escultores..., pág. 199.

48 Bernales Ballesteros, J.: Lima. la ciudad y sus monumentos. Sevilla. 1972. pág. 271. 
ser reconstruidos. El alarife Manuel de Escobar presentó al monasterio una Memoria de las obras que debían realizarse, junto con las «condiciones» analíticas y presupuestadas para tales obras. La citada Memoria comprende tres proyectos diferentes: a) el arreglo de la bóveda vaída sobre la capilla mayor de la iglesia del monasterio; b) el arreglo de las cubiertas del claustro principal; y c) el arreglo general del edificio del monasterio y de sus posesiones en el puerto del Callao. Los alarifes Manuel de Escobar y Manuel de Cevallos tomaron a su cargo las obras de los apartados a) y c); y en las del apartado b) intervino fray Cristóbal Caballero.

Antes de proceder a la reconstrucción de las cubiertas del claustro, fue necesario ejecutar algunos pequeños reparos en las arquerías y pilares levantados por Juan de Mansilla. Entre los trabajos ejecutados por Escobar y Cevallos aparecen algunos reparos de albañilería en el claustro principal. El Libro de Cuentas anota esta salida: el 21 de febrero de 1679, después de haber pagado a Cevallos y Escobar 1.000 pesos, «a cuenta de las obras que están haciendo en el dicho monasterio», añade el contador: «luego incontinente se sacaron 200 pesos que se entregaron al dicho Manuel de Cevallos para que con ellos haga y costee dos arcos en el claustro principal del dicho convento». ${ }^{49}$ Pero es mucho más explícita la liquidación de todos los trabajos archivados en el legajo 6 del monasterio del mismo Archivo Arzobispal, en la que se incluye lo siguiente: «Y así mismo se aderezaron todos los basamentos de los pilares del claustro capiteles y cornisas con ladrillo cortado y se enlucieron los cuatro ángulos del dicho claustro y se blanquearon con dos capas y se sacaron las enjutas de las formas de cal y ladrillo hasta coronar con ellas y se hicieron dos arcos nuevos y se aderezó lo maltratado de los demás y se asentaron los ladrillos cortados y raspados que se arriman a las paredes de dichos ángulos y se pusieron todos los azulejos que

49 Archivo Arzobispal de Lima, Monasterio de Santa Catalina, legajo 1, Libro de Cuentas, folio 118r. 
faltan que importa este reparo seiscientos pesos». Queda así plenamente demostrado que antes de 1678 existía el claustro principal de Santa Catalina, en el que los alarifes Manuel de Escobar y Manuel de Cevallos ejecutaron algunos reparos externos, además de reedificar dos arcos arruinados en ese terremoto. No hay documentación alguna que demuestre que, fuera de tales reparos y de retirar los escombros de las bóvedas de arista derruidas y de volver a solar el piso de los corredores, Escobar, Cevallos o cualquier otro alarife hayan ejecutado los pilares y arquerías del claustro como si en el lugar no existiera antes ningún claustro anterior.

El tercer proyecto presentado por Manuel de Escobar consistió en volver a poner nuevas cubiertas en el antiguo claustro catalino. Como tarea preliminar para esta restauración, se acabaron de derribar todas las bóvedas de arista levantadas por Juan de Mansilla. Así se menciona en los documentos citados del Archivo Arzobispal de Lima. Debe quedar bien claro que los pilares y arcos levantados por Juan Mansilla no necesitaron de otros reparos que los ejecutados por Escobar y Cevallos. Ninguno de estos, ni tampoco tray Cristóbal Caballero tuvo necesidad de volver a construir los pilares y arquerías de este claustro principal.

Formuló también Manuel de Escobar tres alternativas para el proyecto de las nuevas cubiertas del claustro. Dos de las propuestas presentaban cubiertas planas de madera. Una de ellas con cuartones sobre canes «con su tocadura y los cuartones de la misma suerte»; y la otra propuesta sólo incluía simples cuartones cargados sobre las arquerías y las paredes del perímetro externo; y ambas llevarían un solado de ladrillo por encima, como las antiguas bóvedas de Juan de Mansilla. La otra tercera propuesta me rece especial consideración por su originalidad. La podemos descomponer en dos estratos: uno superior de cuartones y tablas para soportar el mismo solado de ladrillo; 'y otro debajo de aquél, formado por unas bóvedas de arista similares a las desbaratadas, pero construidas «de cerchones de madera de roble y yeso de Pisco», pues así lo da a entender la Memoria cuando dice «y volverlo a poner al parecer como lo que se ha derribado». 
Prevalecieron en Santa Catalina los apremios económicos para sufragar tantos reparos como se acumularon al mismo tiempo; y por ello las monjas catalinas optaron por la solución mís ecoinómica de hacer las techumbres planas y sencillas «como los demás claustros». La ejecución de este tercer proyecto estuvo a cargo del mercedario Caballero. Estas cubiertas planas se habían de colocar en los cuatro ángulos del claustro, no solamente en uno de ellos; pues la Memoria de Escobar alude a todo el claustro, y también a sus cuatro ángulos. Ninguno de los documentos de archivo autoriza a limitar los trabajos de fray Cristóbal Caballero a uno sólo de los ángulos del claustro catalino. No he encontrado el concierto notarial para hacer esta obra de las cubiertas, pues tal vez lo pasaron ante Tomás de Paredes, de quien no se conserva ningún protocolo en el Archivo General de la Nación. Pero el precio cobrado por Caballero corresponde a las cubiertas de los cuatro ángulos, según el presupuesto elaborado por Manuel de Escobar en su Memoria para la alternativa más barata. Corren en el Libro de Cuentas del Monasterio las salidas o pagos a fray Cristóbal Caballero desde el 18 de noviembre de 1678 hasta el 15 de octubre de $1680 .{ }^{50}$ La última salida dice a la letra: «... y se sacaron 315 patacones los cuales se entregaron a Fray Cristóbal y con ellos se le acabaron de pagar los seis mil y quinientos pesos en que se concertó la obra del claustro». Nótese que todavía cobró Caballero otros quinientos pesos más del presupuesto inicial presentado por Manuel de Escobar.

No se improvisaba fray Cristóbal Caballero con el trabajo de Santa Catalina de cubrir claustros con techumbres de madera. $\mathrm{He}$ encontrado el concierto notarial de 30 de abril de $1664{ }^{51}$ por el cual don Diego Caballero, su hermano, concertaba las obras de las cubiertas de madera para el segundo claustro del mismo convento de La Merced, terminado en su primera planta por Manuel de Escobar en 1662. La obra del segundo claustro mercedario la concertaba don Diego, pero la ejecutó fray Cristóbal Caballero,

50 Ibídem, folios $119,120 \mathrm{r}$., 120 vt., 121 y 124

51 A.G.N., escribano Juan Fernández Algaba, 1697, protocolo 458, folio 306v. 
según la ficción jurídica empleada en otras oportunidades por los dos hermanos Caballero. Fray Cristóbal era religioso mercedario y por su profesión no podía hacer conciertos notariales de obra sin autorización de sus superiores religiosos. Hay que notar que las obras del claustro de La Merced las pagaba el obispo de Trujillo don fray Juan de la Calle y Heredia, no el convento de La Merced.

6.-La portada principal de La Merced

El historiador mercedario padre Víctor Barriga confiesa en su libro sobre el templo de La Merced de Lima que puso especial empeño por buscar en el Archivo General de la Nación de Lima el concierto notarial para hacer la portada principal de la iglesia; pero sólo logró encontrar el concierto notarial por el que el maestro cantero se obligaba a cortar las piedras de la portada en la cantera; tiene fecha de 11 de julio de $1697 .{ }^{52}$ Este concierto con cl cantero es sumamente sobrio en detalles, pues ni siquiera contiene la Memoria de las piedras que se debían cortar, según aparece en el concierto para cortar las piedras de la portada del convento de San Agustín que he encontrado en el Archivo General de la Nación; y tampoco menciona el nombre del alarife o maestro a cuyo cargo había de estar la portada.

Los trabajos para la portada mercedaria se habían iniciado, al menos, desde principios del año de 1697. Con fecha 17 de enero de ese año se concertó el padre frày Luis Galindo de San Ramón con un arriero llamado Francisco Pérez de Guzmán, para el acarreo de las piedras desde la cantera de Virco en el pueblo de Huamantanga, hasta el convento de La Merced de Lima. ${ }^{53}$ Podemos suponer que según este concierto notarial, las piedras se habrían de cortar según las medidas de cada parte de la portada mercedaria; pues ésta era la norma con que se habían trabajado otras portadas limeñas, como la principal de la catedral, y también la que se siguió para

52 A.G.N., escribano Marcelo Alvartez de Ron, 1697, protocolo 105, folio 168.

53 A.G.N., escribano Jacinto de Narvasta, 1694-1697, protocolo 1.195, folio 361v. 
la portada de San Agustín. Pero el concierto notarial con Francisco Pérez de Guzmán sólo menciona dos tipos de piedras: los tablones y los sillares, sin especificar sus medidas propias.

Este concierto de enero de 1697 incluye la licencia otorgada al padre fray Luis Galindo por su superior religioso. Al señalar que tenía a su cargo toda la obra de las portadas mercedarias, le estaba nombrando obrero mayor, o sea administrador económico de las obras. No debe confundirse este cargo con el de maestro mayor, que era el alarife o arquitecto propiamente dicho; y era el cargo que asignaron anteriormente a fray Cristóbal Caballero, y que sin duda continuaría ejerciendo para la restauración de La Merced. Por estos mismos años, fray Cristóbal Caballero sucedió a fray Diego Maroto como maestro mayor de fábricas reales, o sea como arquitecto oficial del virreinato. Es muy raro que al historiador mercedario padre V. Barriga no se le ocurriera que el arquitecto y diseñador de la portada principal de la iglesia de La Merced de Lima pudiera residir en el mismo convento cuando se estaba construyendo la tal portada; y que pudiera ser un religioso mercedario.

Si nos atenemos a la duración de los cargos de gobierno en la Orden de La Merced, todavía no le sorprendió a fray Cristóbal Caballero el terrible terremoto de 1687 residiendo de nucvo en el convento grande de San Miguel de Lima, pero se reincorporó a él poco después. Los años subsiguientes al terremoto no fueron propicios para concertar encargo de retablos, sino sólo para reedificar los edificios derruidos o dañados en ese temblor. En la iglesia de La Merced de Lima se hundieron las bóvedas vaídas de crucería levantadas con cal y ladrillo. Ahora bien, si en los conciertos notariales de 1671 y de 1681 aparecía fray Cristóbal Caballero ejerciendo el cargo de maestro mayor de obras de su convento y provincia, ahora se presentaba una ocasión mucho más urgente para ejercer ese mismo cargo en una amplitud no sospechada inicialmente, y ante unas urgencias económicas apremiantes que obligaban a autofinanciar las obras para aprovechar mejor los escasos recursos disponibles. ¿Necesitarían acaso los religiosos mercedarios buscar un maestro de obras extraño para dirigir las reedificaciones 
del convento e iglesia, teniendo en casa una persona de toda competencia y experiencia, como lo era fray Cristóbal Caballero.

A pesar del silencio de los historiadores del arte, sabemos que fray Cristóbal Caballero estaba suficientemente capacitado para dirigir la reconstrucción de $\mathrm{La}$ Merced después del terremoto de 1687. Si tras la muerte de fray Diego Maroto, la ciudad de Lima le encomendó el cargo de maestro mayor de fábricas reales, ello se debía no tanto a las labores que pudo haber desempeñado anteriormente, cuanto a las tareas actuales que asumiría en su propio convento después de octubre de 1687. Sabemos también que fray Cristóbal Caballero ejerció este oficio interviniendo en obras importantes. No fue sólo el famoso Informe acerca de la catedral publicado por Diego Angulo Iñiguez; ${ }^{54}$ o también la noticia de que fray Cristóbal Caballero asesoró al gobernador Lagúnez como maestro mayor de fábricas reales en el reconocimiento de los socavones subterráneos en las minas de Huancavelica, publicado por Lohmann Villena; ${ }^{55}$ sino también las «condiciones» preparadas para la tasación y adjudicación de los reparos de la muralla de Lima, preparadas en unión del ayudante de ingeniero Pedro de Asencio, en lo que demuestra a cabalidad dominar las técnicas y recursos del oficio de arquitecto y de constructor: se incluyen estas condiciones como Anexo según el concierto notarial firmado el 16 de julio de $1698 .{ }^{56}$ Se conoce también la intervención de fray Cristóbal Caballero en el pleito suscitado contra el ensamblador José de Castilla por otro ensamblador llamado Diego de Rojas que pretendía quedarse con el encargo de tallar el retablo para la capilla de Nuestra Señora de los Remedios en la iglesia de La Merced. En este pleito replicaba así el ensamblador Castilla: «Primero porque con la tasación del maestro mayor fray Cristóbal Caballero quedó ajustado el contrato...». ${ }^{57}$

54 Angulo Iñiguez, D.: Planos de monumentos arquitectónicos de América y Filipinas, Sevilla, 1939, Apéndice documental.

55 Lohmann Villena, G.: Las minas de Huancavelica en los siglo XVI y XVII, Sevilla, 1949, págs. 433. Cita la carta de Lagúnez de fecha 2 de diciembre de 1699.

56 A.G.N., escribano Diego Fernández Montano, 1698, protocolo 502, folio 666.

57 Archivo Arzobispal de Lima, Cofradía de Ntra. Sra. de los Remedios, siglo XVIII, legajo 25 , sin numeración de folios. Alegato de José de rastilla de fecha 27 de enero de 1702. 
Como prueba decisiva de la intervención de fray Cristóbal Caballero en la reedificación de la iglesia de La Merced después de 1687, vislumbramos este significativo detalle: en las pilastras de las columnas y en los arcos fajones y torales de la nueva iglesia se emplea el esgrafiado de grandes figuras geométricas en las que alternan óvalos y rectángulos. Aun cuando Wethey supone que esta decoración «mudéjar» recuerda los antecedentes andaluces, que difiere de la decoración empleada en las iglesias de Quito, ${ }^{58}$ la verdad es que encontramos un antecedente inmediato de esta decoración esgrafiada de La Merced de Lima en el monumento a Carlos II, obra documentada de fray Cristóbal Caballero, reproducida en el grabado de Pedro Nolasco; a los lados del monumento se elevan dos delgadas pirámides adornadas en su frente con la misma alternación de grandes óvalos y figuras rectangulares. Sucedió, pues, que el mismo fray Cristóbal Caballero reiteró en la iglesia de La Merced la ornamentación que él había introducido en las pirámides del monumento a Carlos II.

La portada principal de La Merced muestra aspectos específicos que permiten identificar las modalidades estilísticas empleadas por su autor en otras obras suyas. Como aspecto general, esta portada destaca entre las grandes portadas limeñas por su rotundo planteamiento volumétrico. Todo el bloque de la portada mercedaria resalta en gran manera sobre el muro a que se antepone; además de que sus dos calles laterales quedan retrasadas con relación a la calle central. Esta era la misma disposición desarrollada en el monumento a Carlos II y también en la portada del monasterio de Santa Catalina. Dentro de esta disposición del volumen, tan específica de Caballero, resulta coherente el paso desde los bloques de tres columnas usados en el monumento y en el retablo de la Santísima Trinidad, a las dos columnas en distinto plano colocadas en la portada mercedaria.

El desarrollo volumétrico conlleva otras derivaciones en $\mathrm{cl}$ estilo peculiar de fray Cristóbal Caballero. Los cuerpos segundo

58 Wethey, Colonial..., pág. 74. 
y tercero de la portada de Santa Catalina quedaban más retrasados, quebrando hacia adentro el paramento más extenso de la portada, como una medida de seguridad antisísmica, tan necesaria en Lima. Sin duda, por el mismo motivo se reitera en la portada mercedaria el retraimiento de los cuerpos superiores hacia adentro, quebrando la línea externa de la portada. Este efecto resulta todavía perceptible en la reconstrucción actual de la portada realizada por Harth-Terré; pero destaca mucho más notoriamente en las fotografías antiguas de la misma portada, como la que publica Wethey fechada hacia $1890 .^{59}$ Desde luego, no encontramos en Lima ninguna otra portada virreinal en la que reaparezca la línea quebrada antisísmica de sus cuerpos, como la impuesta por Caballero en las portadas de Santa Catalina y de La Merced.

Se ha expuesto el ingenioso recurso mediante el cual fray Cristóbal Caballero plasmaba en los cuerpos de gran volumen del monumento a Carlos II y en el retablo de la Santísima Trinidad un efecto de perspectiva logrado al poner arcos interiores más bajos y menores que los arcos externos del frente. Este mismo efecto es sobremanera notorio y resaltante en los tres cuerpos de la calle central de la portada de La Merced. En su primer cuerpo, el vano de entrada a la iglesia se adorna con dos arcos a distinto nivel: el exterior es de aspecto claramente peraltado; y el interior queda más bajo y rebajado; unidos ambos arcos con mucha galanura mediante la gran venera. Corona el gran balcón del segundo cuerpo un arco trilobulado del estilo de los que prodigaba José de Castilla en sus retablos durante el primer tercio del siglo XVIII; pero aquí también se objetiva el mismo efecto de perspectiva volumétrica; pues detrás del primer arco externo, aparece otro arco similar más bajo y estrecho. Y en el óvalo vacío del tercer cuerpo se reitera el mismo efecto de perspectiva con el arco del fondo más bajo que el arco exterior. Ninguna otra portada virreinal de Lima muestra este efecto de perspectiva descrito en las «condiciones» establecidas por Caballero para el retablo de la Santísima Trinidad, y aplicado igualmente en el monumento a Carlos II.

59 Ibidem, lámina 110. 
En el Sagrario ensamblado por Asensio de Salas introdujo fray Cristóbal Caballero unas curiosas «cortezas que abracen el alquitrabe y miembros de la cornisa». Si quisiéramos identificar este adorno mencionado por dos veces en el concierto notarial con el monasterio de las Bernardas, no tendríamos expediente más fácil que acudir al arco exterior del vano de entrada en la portada principal de La Merced. Aquí encontramos cinco de esas cortezas o abrazaderas ciñendo las dos impostas o molduras de la rosca del arco: también es este un recurso ornamental singular, no reiterado en otros retablos o portadas limeñas.

Tienen igualmente cabida en la portada de La Merced otros detalles ornamentales usados por fray Cristóbal Caballero. A semejanza del retablo de la Santísima Trinidad, en cuyo tercer cuerpo ponía en las pilastras «unas mensulillas o cargadores que sustenten la arquitectura de arriba», también se ponen en la misma posición y con idéntica finalidad tales adornos en el tercer cuerpo de La Merced. A lo cual se añaden otros niños cargadores que soportan la rosca del arco exterior de la entrada. Los pedestales de las columnas se adornan en La Merced con «medias tarjillas que correspondan a los pedestales de las columnas principales», como en el retablo de la Santísima Trinidad. Y tanto en La Merced como en este retablo, «los muros de los lados de los nichos port encima se han de guarnecer con recuadrillos de molduras talladas o tarjillas largas y estrechas», según se observa en los cuatro nichos laterales mercedarios, en los cuales aparecen fajas de escamas imbricadas.

Me atrevo a pensar que para atribuir a fray Cristóbal Caballero la paternidad sobre la portada principal de La Merced, las afinidades estilísticas demostradas entre la misma portada y otras obras auténticas del mercedario suplen con creces la ausencia de fuentes documentales, pues tienen tanta o más fuerza probatoria que las referencias escritas. Más bien, tomando en consideración la trayectoria como alarife y ensamblador de fray Cristóbal Caballero y el cargo de maestro mayor de fábricas que desde antiguo venía desempeñando en el convento de La Merced, lo extraño e inexplicable hubiera sido que cualquier otro alarife ajeno a la 
Orden Mercedaria fuera llamado para diseñar la traza de la obra arquitectónica más notable de La Merced. Los agustinos no emprendieron la portada principal de su iglesia limeña hasta no haber terminado de restaurar el convento grande de Lima. Pero los mercedarios, tallaron la portada de su iglesia, obra de pura ornamentación y por lo tanto innecesaria, cuando todavía pasaban penurias con el convento grande de San Miguel en ruinas. Apremiaba a ello la impaciencia de fray Cristóbal Caballero, temeroso de que la muerte le impidiera continuar su proyecto. El historiador-arquitecto Harth-Terré imagina los últimos años de fray Cristóbal Caballero estimulado en el descanso y reposo por la grata complacencia de las obras ejecutadas. En realidad, los trabajos de los años precedentes no fueron para él sino entrenamiento y maduración para realizar la gran obra que todavía le quedaba: la reconstrucción de la iglesia y diseñar la traza para la portada principal de ésta. Aquí remansaron en sosegado acopio sus experiencias, sus creaciones volumétricas, sus singulares motivos ornamentales, su configuración de la perspectiva, y aquella efusiva libertad creadora que le movía a establecer en sus conciertos que «si me pareciera añadir para mayor crédito de mi obra alguna cosa a la arquitectura o ensamblaje lo he de poder hacer sin que por ello se me haya de dar más cantidad que la que va declarada en esta escritura», la del concierto de la Santísima Trinidad. A fray Cristóbal Caballero le llegó su gran oportunidad para ejercer el arte de la arquitectura, que le nacía de dentro, cuando se encon traba al final de su vida. Correspondió generosamente a este don de Dios; y acaso lograra contemplar terminada antes de morir, hacia 1702, la portada que acaso nunca hubiera soñado con poder alumbrar, de no haber acaecido el terremoto de 1687 .

\section{Antonio San Cristóbal Sebastión}




\section{ANEXOS DOCUMENTALES}

CONCIERTO DEL, PADRE FRAY CRISTOBAL CABALLERO CON LA MADRE ABADESA DEL MONASTERIO DE SANTA CATALINA DE SENA PARA HACER LA PORTADA DE LA IGLESIA DEI, MONASTERIO *

En la ciudad de los Reyes en ocho días del mes de abril de mil y seiscientos y setenta y un años ante mí el escribano público y testigos parecieron el Padre Predicador Fray Cristóbal Caballero religioso del Orden de Nuestra Señora de Las Mercedes Redención de Cautivos en el Convento Grande de esta ciudad maestro mayor de obras del dicho su Convento y en virtud de la licencia que tiene de su Prelado que es su tenor a la letra como se sigue:

Fray Juan Centeno Presentado en la Sagrada Teología Doctor en la Real Universidad y Comendador de este Convento Grande de San Miguel de Lima del Orden de Nuestra Señora de las Mercedes Redención de Cautivos por cuanto tenemos hecho nombramiento de maestro mayor de todas las obras de este dicho Convento al Padre Predicador Fray Cristóbal Caballero religioso profeso y sacerdote de nuestra sagrada Religión atento a la pericia que tiene en su arte por tanto para que pueda tener alguna utilidad para poder llevar el peso de las que porr parte del dicho Convento se le encomienden a que acude con toda prontitud le damos licencia para que pueda hacer todas y cualquiera obras que quisieren encomendarle fuera del dicho Convento concertándolas según que le parezca y fuere de su utilidad y pueda obligar y obligue sus bienes al seguro y sanamiento de ellas y le damos esta licencia tan amplia como puedo y por derecho se requiere de suerte que por falta de ella no deje de hacer todo lo que en este arte se le ofrezca y porque conste le damos la presente firmada de nuestro nombre sellada con el sello de la Orden y refrendada por el presente secretario en seis días del mes de abril de mil y seiscientos y setenta y un años de la folio 832).

* (A.G.N., escribano Marcelo Antonio de Figueroa, 1671, protocolo 667, 
Asunción de la Virgen Santísima Nuestra Madre y de la revelación y fundación de nuestra Sagrada Religión cuatro cientos y cincuenta y tres años. Fray Juan Centeno Comendador. Por mandato del Rdo. Padre Comendador Fray Nicolás Ruiz Secretario.

Prosigue. Y usando de la dicha licencia susoinserta el dicho Padre Fray Cristóbal Caballero de la una parte y de la otra la Madre María del Salvador Abadesa del Monasterio de Monjas de Santa Catalina de Sena de esta dicha ciudad a quienes doy fe conozco y de un acuerdo y conformidad por el tenor de la presente otorgaron que son convenidos y concertados en esta manera.

Que el dicho Padre Fray Cristóbal Caballero se obliga de hacer la portada principal de la iglesia del dicho Monasterio que cae a su plazuela de piedra de Arica y ladrillo a todo costo según y en la forma de la planta y diseño que está hecha y queda en poder del dicho Padre Maestro para ejecutarla la que queda firmada de ambas partes y del presente escribano público y la dicha obra se obligó a hacer en la forma y con las condiciones siguientes:

Primeramente con condición que se ha de hacer la dicha portada de albañilería y cantería y para ello se han de sacar los cimientos necesarios desde lo firme y sobre ellos se ha de plantar los pedestales de cantería labrada de piedra de Arica hasta dos varas de alto y de ancho dicha portada nueve varas menos sexma de fuera a fuera por las barras de los pedestales y el hueco de dicha portada de ancho de una jamba a otra cuatro varas menos sexma y de alto por la clave seis varas y una sexma de hueco $=y$ toda la dicha portada ha de levantar quince varas y media sin los remates ni pedestales de ellos inclusive el frontis último y de alli para arriba los remates ejecutándose la traza hecha por el dicho Padre Fray Cristóbal Caballero susoreferida con todos sus adornos añadiendo en el segundo cuerpo capiteles corintios en lugar de los toscanos que tienen las pilastras las cuales han de ser como parecen en la traza con los relieves necesarios para que las impostas del arco principal se incluyan como demuestra la traza y todos los vuelos de las cornisas y gruesos de molduras y demás adornos han de tener lo necesario según arte $=\mathrm{y}$ de buenos materiales de ladrillo cal $\mathrm{y}$ arena con tablones y pasteleros donde fueren necesarios bien cocidos y de 
buen barro toda la dicha portada de ladrillo desde las dos varas de cantería para arriba y barro cocido de ollería = todas las tallas de serafines marioletas y fruteros y capiteles y los santos que se han de poner en la dicha portada que irán declarados en esta escritura así mismo han de ser de barro cocido $=\mathrm{y}$ todo lo demás entallado perfilado y enlucido de buena mezcla de cal y arena cernida delgada $=$ y toda la dicha portada del color que se le ordenare poniéndole sus remates y cruz de madera dados de barniz para que no se pudran con el mismo color también de la portada con su cardinel abajo de piedra labrada con toda la cantería bien ejecutada de piedra de Arica que no es salitrosa porque no se coma el ladrillo = con declaración que al plantar las basas de los pedestales se les han de dar el relieve necesario para que habiendo disminuido para adentro segundo y tercer cuerpo se quede cl relieve necesario de la pared para afuera a los algotantes y resaltos de las traspilastras de suerte que por las cañas de las pilastras del segundo cuerpo tengan tres cuartas de relieve antes más que menos y toda la dicha obra bien trabada con la pared de adobería entregándose en el macizo de ella media vara con la albañilería de ladrillo y por partes dos tercias para que quede seguro de temblores todo bien acondicionado a ley de buena obra a vista y satisfacción de las personas que se nombraren para ello por parte del dicho Monasterio y todo ello se ha de hacer a toda costa de materiales y manufactura hasta dejarla acabada en toda perfección en precio de tres mil y doscientos pesos de a ocho reales pagados en esta manera: los un mil pesos de ellos que se han de dar de contado al dicho Padre Fray Cristóbal Caballero para comenzar la dicha obra $=$ y otros mil pesos dentro de cuatro meses de la fecha de esta escritura en adelante y los mil doscientos pesos restantes acabada la obra en toda perfección que ha de ser para fin de noviembre de este presente año de mil y seiscientos y setenta y uno = Item se declara que los santos que se han de poner en la dicha portada son en el cuerpo principal Nuestra Señora del Rosario, en el remate San Miguel Arcángel a los dos lados Santo Domingo y Santa Catalina de Sena $=$ y es condición de esta escritura que si el dicho Padre Maestro Fray Qristóbal Cahallero no hiciere la dicha obra y la diera acabada al plazo referido en esta escritura pueda la Madre Abadesa que fuere del dicho Monasteriorio mandarla hacer con otro maestro de este arte y por lo que más 
le faltare de los dichos tres mil y doscientos de este concierto ha de poder ser ejecutado ... (siguen cláusulas de obligación)... y los dichos otorgantes a los cuales yo el presente escribano público doy fe conozco lo firmaron estando en la portería del dich• Monasterio don Félix de M. Francisco de Alcorta el licenciado don Agustín de Peralta y Francisco de Illescas

María del Saivador Ahadesa $\quad$ Fray Cristóbal Cahallero
Marcelo Antonio de Figueroa
escribano público

\section{CONCIERTO DEI, MONASTERIO DE LA SANTISIMA TRINIDAD CON EL. PADRE FRAY CRISTOBAL CABALLERO PARA HACER EL RETABLO DEL ALTAR MAYOR*}

Sepan cuantos esta carta vieren cómo yo doña Marcela de Aguilar Abadesa del Monasterio advocación de la Santísima Trinidad en esta ciudad de los Reyes del Perú = (sigue la petición al Cabildo Metropolitano y la licencia de éste para hacer la escritura del concierto)... Y usando de la dicha licencia yo la dicha doña Marcela de Aguilar como tal Abadesa en nombre del dicho Monasterio y de las Religiosas que al presente son y adelante fueren de la una parte $=$ y de la otra yo el Padre Predicador Fray Cristóbal Caballero del Orden Real de Nuestra Señora de las Mercedes Redención de Cautivos Maestro arquitecto en virtud de la licencia de mi prelado que es del tenor siguiente: Fray Juan Centeno presentado en Sagrada Teología Doctor en la Real Universidad y Comendador de este Convento grande de San Miguel de Lima del Orden de Nuestra Señora de la Merced Redención de Cautivos por la presente doy licencia al Padre predicador Fray Cristóbal

* (A.G.N., escribano Tomás de Quesada, 1671-1672, protocolo 1.571, folios 190r.-195v.). 
Caballero, profeso sacerdote de Nuestra Sagrada Religión y Maestro Mayor de todas las obras de esta Provincia para que pueda hacer y haga todas aquellas que por razón de su arte se le ofrecieren concertándolas así de palabra como por escrito con escritura o sin ella y en especial para que pueda hacer y haga el retablo del altar mayor del Monasterio de Monjas de la Santísima Trinidad de esta ciudad = Otro sí le doy esta licencia para que pueda parecer y parezca en juicio y fuera de él a demandar y pedir lo que por razón de dichas obras le perteneciere y a la firmeza de todo pueda obligar y obligue los bienes que ad ius Ordinis tiene que para todo le doy esta licencia y tan bastante cuanto de derecho se requiere y es necesario y porque así conste di la presente firmada de mi nombre sellada con el sello de la Religión y refrendada por el presente Secretario en primero día del mes de octubre de mil y seiscientos y setenta y un años y de la descensión de la Virgen Santísima Nuestra Señora a la fundación de Nuestra Sagrada Religión cuatrocientos y cincuenta y cuatro Fray Juan Centeno Comendador. Por mandato del Reverendo Padre Comendador Fray Nicolás Ruiz, Secretario.

Y de ella usando nos ambos dos dichos otorgantes decimos que estamos convenidos y concertados en tal manera que el dicho Padre Maestro se obliga como por la presente me obligo de hacer un retablo para la capilla mayor del dicho Convento de la Santísima Trinidad que ha de tener todo el ancho de su capilla y de alto todo el que así mismo tiene según y en la forma y manera que demuestra la planta y norma que queda en poder de mí el dicho Padre Fray Cristóbal Caballero firmado del Señor doctor don Juan Santoyo de Palma arcediano de esta Santa Iglesia que está presente al otorgamiento de esta escritura en conformidad de lo dispuesto por la licencia de susoinserta y de ambos otorgantes y el presente escribano para según y en la forma que en ella se contiene disponer y acabar el dicho retablo con todos los repartimientos y nichos que en ella se demuestran sin exceder en cuanto a disminuirla en cosa alguna de su tenor y forma y la dicha obra me obligo de hacer con cargo de guardar y cumplir las condiciones siguientes:

la primera que para veinte de agosto del año próximo venidero de mil seiscientos y setenta y dos día del glorioso San Bernardo he 
de dar puesto el primer cuerpo en blanco acabado en toda perfección sin que le falte cosa alguna conforme a dicha planta y dibujo $=\mathrm{Y}$ el segundo cuerpo para del dicho día veinte de agosto en seis meses $=$ Y de ahí en otros seis el tercer cuerpo y resto del dicho retablo por manera que todo él ha de quedar puesto a los plazos referidos para veinte de agosto de mil seiscientos y setenta y tres.

Item. con condición que para haberse de poner dichos cuerpos y retablo he de ser obligado para que quede la testera en la perfección que se requiere al arte de bajar tres gradas una de las dos sobre que está formado dicho altar mayor y las otras dos del presbiterio si pareciere convenir al Monasterio y si no dejarlo como se está = Con declaración que hahiéndose de hajar lo que se gastare en ello lo ha de dar y pagar el dicho Monasterio sin que se me descuente del precio. en que está concertado dicho retablo.

Item. condición que los cuartos de columnas del primero segundo cuerpo han de ser enteras quitando las traspilastras a la columna j)rincipal o dejando dichas traspilastras en el ancho de las columnas y sólo en esta calidad he de tener facultad para reconocer si es más a propósito que queden en cuartos los entrecolumnios o que sean enteros y dichas columnas grandes y pequeñas se han de revestir más de lo que están en dicho dibujo al modo que lo están las del retablo de la capilla mayor del Monasterio de Monjas de Nuestra Señora de la Encarnación.

Item. condición que el Sagrario sobre el segundo cuerpo se ha de acompañar con más obra por delante y los lados $=\mathrm{Y}$ en los frisos del primer cuerpo de dicho Sagrario unas cortezas que abracen el alquitrabe y miembros de la cornisa y en ellas las mansulillas que hoy tiene y lo mismo en los del segundo cuerpo y desde la media naranja del encima del Sagrario alquitrabe en que remata el arco de la Virgen esté encarcelada la media naranja y la interna que sea una urna que sirva de plan al Santo Cristo y en cuanto a la caja que comprende el dicho Sagrario se ha de cubrir como bóveda vaída ovalada porque no embarace mucho el relieve y el arco de la espalda ha de ser menor que el de afuera para que vaya siempre manifiesto a la vista los ladosb Y la cubierta que va sobre los cuatro arcos dos pequeños en los lados y uno en la testera menor que el de afuera. 
Item. con condición que los bancos del segundo cuerpo han de llevar sus medias tarjillas que corresponden a los pedestales de las columnas principales y en los de abajo que caiga una hoja del motilo para abajo y en esta conformidad se ha de guarnecer el resto del retablo y acompañar los segundos cuerpecillos que rompen la cornisa principal del primer cuerpo y estos tablerillos se minoren y lleven frontispicios como lo es el del medio con ángeles recostados con instrumentos de música de segundo cuerpo el cual se ha crecer respecto del todo porque el que está hace poca consonancia a la máquina del todo además de estar alto y disminuirla.

Item. condición que los Santos que se han de poner en los nichos que tuvieren en la calle que acompañan el Sagrario han de ser redondos en la escultura los cuales y todos los demás que se han de poner en dichos nichos han de ser los que dijera la dicha Abadesa por su devoción.

Item. condición que la repisa que hoy sirve y está para el Santísimo se ha de guarnecer con sus rostrillos y la de la Santísima Trinidad poniendo cada una seis cornucopias y resaltando en la parte del Santo Cristo la peana y respecto que en el nicho que está hecho para el Santo Cristo se ha de poner otra hechura se podrá acortar por la cabeza para que la tarja crezca dejándolo a lo menos de vara y tercia de alto para que en él se ponga el Santo que después se advirtiere $=\mathrm{Y}$ los muros de los lados de los nichos por encima se han de guarnecer con recuadrillos de molduras talladas o tarjillas largas y angostas.

Item. condición que en la basa de la talla de la Santísima Trinidad después de haber dejado en el resalto que ha de tener la cantidad necesaria para que haya en ella seis cornucopias en que se pongan las luces y suficiente capacidad para que entre cornucopia y cornucopia se pongan ramos en el resto de adentro de dicho plan una portañuela aquí y en todos los demás nichos para que por ella se aderecen y pongan las luces sin que se vean de la parte de afuera para que no sea necesario hacerlo con escalera y si pareciere al dicho Padre Fray Cristóbal que la portañuela se reduzca a que se abra todo el nicho hacia adentro engoznando jor un lado o en dos mitades para que habiendo dejado en el plan de dichos nichos capacidad de suelo por detrás del retablo se puedan retirar los Santos para adentro y que sea más cómodo 
el poder aderezar con flores y velas las peañas o repisas y vestirlos y que quepa la persona que lo ha de hacer porque de la otra forma no es posible por el embarazo que hace el Santo en el dicho nicho -$Y$ de la misma forma tengan bastante resalto las peanas de dichos nichos para dichas cornucopias y ramos de flores de su adorno

Item. condición que los bancos del Sagrario se han de enriquecer con algunas cortezas que abracen las molduras así de los pedestalillos como de los recuadros.

Item. condición que dicho retablo se ha de dar asentado fijo en carnes y tornapuntas con declaración que todo el molduraje y tallas se ha de hacer en madera de cedro.

Item. condición que las puertas principales del Sagrario han de. tener a San Pedro y San Pablo de media talla poco relieve con sus moldurillas talladas que ciñen los bultos y que se reduzca a dos nichecillos largos y angostos.

Item. condición que en las pilastras del tercer cuerpo adonde están las frutas se han de poner unas mensulillas o cargadores que sustenten la arquitectura de arriba.

ltem. condición que la talla de la Santísima Trinidad y los bultos de los gloriosos Padres San Benito y San Bernardo han de ser los mismos que hoy tiene la dicha capilla mayor que sólo los recibo yo el dicho Padre para vestirlos con más perfección y adorno con advertencia que los bultos de dicha talla han de llevar más relieve del que al presente tiene.

Prosigue. Y toda la dicha obra la he de dar acabada en la forma que se contiene en dicha planta de que va hecha mención y si me pareciere añadir para mayor crédito de mi obra alguna cosa a la arquitectura o ensamblaje lo he de poder hacer sin que por ello se me haya de dar más cantidad de lo que irá declarado en esta escritura. Y a los plazos y en la forma que se contiene en las condiciones insertas me obligo de guardar y cumplir en todo y por todo según como en ellas se contiene $=\mathrm{Y}$ por todo ello se me ha de dar y pagar catorce mil pesos de a ocho reales en la forma y a los plazos siguientes: los cinco mil trescientos y veinte y siete pesos de ellos que tengo recibidos adelantados en esta manera: tres mil seiscientos y cuarenta y cuatro pesos en el valor del Sagrario bancos columnas y tarjas sueltas que habia 
hecho Asensio de Salas con quien primeramente se había concertado la dicha obra que es el precio en que se tasó todo lo referido por mandato del Juez Ordinario de este Arzobispado y se le adjudicó al dicho Monasterio en dicha cantidad por cuenta de la que había percibido el dicho Asensio de Salas para la obra del dicho retablo. Cuatro cientos pesos en que se tasó la talla de la Santísima Trinidad dos cajas de ángeles de cuerpo entero grandes y los dichos bultos de San Benito y San Bernardo y los tableros en que al presente están $=$ seiscientos pesos del valor de doce vigas las siete enteras y las cinco aserradas $=$ treinta y tres pesos del aserrío de las cinco dichas vigas $=$ seiscientos y cincuenta pesos del valor de un negro nombrado José Manrique de la Santísima Trinidad de que me ha de hacer venta en esta escritura la dicha Abadesa $=$ por manera que todas las dichas partidas suman y montan los dichos cinco mil trescientos y veinte y siete pesos de los que en esta forma referida me doy por contento y entregado a mi voluntad y porque su recibo de presente no parece renuncio la excepción del derecho leyes de la nonumerata pecunia prueba del recibo y demás del caso como en ellas se contiene $=\mathrm{Y}$ los ocho mil seiscientos y setenta y tres pesos restantes cumplimiento a los dichos catorce mil pesos de este concierto que se me han de pagar los un mil seiscientos y setenta y tres pesos de ellos luego que empiece la dichia obra - - Tres mil y quinientos pesos en el término inclusive de los seis meses en que se ha de poner el segundo cuerpo que me los ha de ir pagando la dicha Abadesa como los tuviere $=$ dos mil quinientos pesos en el término inclusive de los seis meses últimos del tercer cuerpo y resto del dicho retablo y los un mil pesos restantes cumplimiento a toda la dicha cantidad así que esté acabada de poner la dicha obra y en toda perfección el dicho retablo y todas sus esculturas todo lo cual cumpliré a los plazos referidos pena si así no lo hiciere y cumpliere de pagar y que pagaré al dicho Monasterio todos los daños que sobre ello se le siguieren y recibieren para cuya seguridad doy por mi fiador a don Diego Caballero, mi hermano vecino de esta dicha ciudad y yo el susodicho que presente soy a lo concertado en esta escritura otorgo que me obligo en tal manera que el dicho Padre Fray Cristóbal Caballero mi hermano cumplirá en todo y por todo con el tenor y forma de esta escritura según y como en ella va declarado y dará hecho y acabado 
el dicho retablo según demuestra en dicha planta y condiciones de esta escritura y a los plazos en ella referidos y en su defecto pagará los dichos catorce mil pesos o la parte que de ellos le hubieren dado con más los daños y menoscabos que en dicha razón se le siguieren al dicho Monasterio donde no y como tal su fiador y llano pagador que me constituyo por el dicho mi hermano haciendo como para ello hago de deuda y negocio ajeno mío propio y de libre deudor volveré y pagaré al dicho Monasterio toda la cantidad de pesos que constare haber recibido el dicho mi hermano por cuenta de dicha obra y las costas y daños y menoscabos que de no haberla acabado se le hubieren seguido al dicho Monasterio llanamente y sin pleito con las de la cobranza Y lo haré y cumpliré sin que contra el susodicho ni sus bienes ni otra ninguna persona ni los suyos sea hecha ni se haga diligencia ni exclusión de fuero ni de derecho cuyo beneficio y remedio con el de las auténticas esperas y expensas especial y expresamente renuncio a cuya firmeza paga y cumplimiento obligamos yo el dicho Padre Fray Cristóbal Caballero mis bienes y cuantos tengo ad usus ordinis y yo dicho Diego Caballero mi persona y los míos y de ambos habidos y por haber $=\mathrm{Y}$ yo la dicha doña Marcela de Aguilar como tal Abadesa que presente soy acepto esta escritura en favor del dicho Monasterio según y como en ella se contiene y por cuenta de los catorce mil pesos del concierto de ella declaro haber recibido el dicho Padre los tres mil seiscientos y cuarenta y cuatro pesos que contienen las partidas de suso en que se incluyen los seiscientos y cincuenta pesos del valor del negro Joseph Manrique de la Santísima Trinidad el cual por el tenor de la presente se lo vendo al dicho Padre ... (sigue la venta del esclavo)... y los ocho mil seiscientos y setenta y tres pesos restantes cumplimiento de los dichos catorce mil que obligo al dicho Monasterio de se los dar y pagar al dicho Padre y a quien su causa hubiere a los tiempos y plazos que van referidos en esta escritura y antes si antes los tuviere porque si antes los tuviere se los daré y pagaré sin que sea menester aguardar a que se cumplan dichos plazos

Y a la firmeza paga y cumplimiento de lo que dicho es obligo ... ( siguen las cláusulas notariales de cumplimiento)... en la ciudad de los Reyes del Perú estando en la portería principal del dicho Monasterio de la Santísima Trinidad en presencia y con asistencia del Sr. Dr. D. 
Juan Santoyo de Palma arcediano de esta Santa Iglesia en primer día del mes de octubre de mil y seiscientos y setenta y un años y todos! los dichos otorgantes a quienes, yo el escribano doy fe conozco la firmaron siendo don Joseph Gutiérrez de Ocampo colegial del Real de San Martín Juan de Santana y Lorenzo Contero presbítero

\author{
Juan Santoyo de Palma \\ Abadesa \\ doña Marcela de Aguilar \\ Fray Cristóbal Caballero \\ Diego C. \\ Tomás de Quesada escribano de Su Magestad
}

CONCIERTO DE FRANCISCO JAVIER DOMINGUEZ CON EL
CONVENTO DE LA MERCED PARA HACER EL NOVICIADO *

Sepan cuantos esta carta vieren cómo en la ciudad de los Reyes del Perú a seis días del mes de junio de mil y seiscientos y setenta y nueve años ante mi el presente escribano público y testigos parecieron de la una parte los Muy Reverendos Padres Maestros Fray Santiago de Pastrana, Provincial del Orden Real de Nuestra Señora de La Merced redención de cautivos y Fray Juan Centeno, Comendador de este Convento grande de Lima del mismo Orden y de la otra parte Francisco Javier Domínguez, maestro alarife de esta ciudad a quienes doy fa conozco y dijeron que por cuanto el dicho M.R.P. Provincial tiene aplicados los bienes expolios que quedaron por fin y muerte del M.R.P. Fray Diego Serrano difunto Provincial pretérito que fue de dicha Provincia para efecto de labrar y que se labre en dicho Convento grande un Noviciado y celdas en que vivan los religiosos de él por haber mucha necesidad de que se haga esta fábrica en cuya conformidad y para el dicho M.R.P. Comendador se ha convenido y concertado como por el tenor de la presente se conviene y concierta con el dicho maestro siguientes).

* (A.G.N., escribano Nicolás García, 1679, protocolo 7£0, folios 253r. y 
Francisco Javier Domínguez en tal manera que el susodicho ha de hacer la fábrica del dicho Noviciado y celdas en la forma y según que se contiene en la planta y modelo (que está hecho en un papel firmado de todos los otorgantes y de mí el presente escribano sin exceder de él en cosa alguna lo cual ha de hacer bien y cumplidamente y a satisfacción del Padre Predicador Fray Cristóbal Caballero religioso del mismo Orden a toda costa poniendo el dicho maestro todos los materiales necesarios para la dicha fábrica y los oficiales y peones que fueren menester para que en toda brevedad se ajuste y acabe y la ha de empezar luego desde el lunes que viene que se contarán doce del corriente trabajando en ella todos los días de trabajo sin omitir ninguno la cual dicha obra se le ha de pagar al dicho maestro en esta manera primeramente que por todos los adobes que se pusieren y asentaren en lo alto y bajo de la dicha fábrica se le han de dar y pagar a razón de cincuenta y dos pesos por cada millar.

Iten la mampostería de las paredes cercanas a la acequia del sitio que está señalado que son cincuenta varas cúbicas más o menos los que fueren se le han de pagar a seis pesos de a ocho reales cada vara haciéndolas el dicho maestro a toda costa.

Item por debajo de las dichas cincuenta varas de mampostería ha de haber otras tantas de cimientos de piedra y cal y ha de ser otra vara debajo de tierra y éstas se le han de pagar a razón de tres pesos y cuatro reales.

Item por lo tocante a la albañilería de los tres arcos y pilares puerta de la capilla y entrada del arco del noviciado que corresponde a la puerta de él se le ha de pagar a razón de diez pesos de a ocho reales por cada vara cúbica en lo que así fuere de albañilería cal y ladrillo $=\mathrm{Y}$ al mismo precio la acequia que se ha de echar por la calle y así mismo toca a albañilería.

Item que respecto del precio señalado en las partidas aquí contenidas se le ha de pagar todo lo que montaren en esta manera

Primeramente un mil y quinientos pesos de a ocho reales en viniendo el navío en que viene embarcado de tierra firme el capitán Francisco de Paredes cuarenta días después de haber dado fondo en 
el puerto del Callao y las demás pagas se las ha de ir haciendo el M.R.P. Comendador conforme se fuere ofreciendo sin que se le haga falta para la prosecución de dicha obra con descuento de lo que importaren los jornales de los negros que el dicho M.R.P. le diere de los que el dicho Convento tiene para peones de ella que ha de tener hecha cl dicho maestro como también el dicho M.R.P. Comendador en su libro para el ajuste de la paga que se obliga de hacer a dicho maestro y si acabada la obra se le restare por pagar alguna cantidad se le ha de pagar y satisfacer luego de contado con costas de la cobranza en fuerza de esta escritura que ha de ser para ello exigible de aparejada expresamente y en la dicha forma se obligó el dicho maestro a hacer la dicha fábrica con toda la brevedad posible empezándola luego desde el día señalado que se le contarán doce de este presente mes y año continua. mente sin hacer falta y si la hiciera de por enfermedad u otro accidente ha de poner maestro que la continúe y acabe y en su defecto le ha de buscar el dicho Padre Comendador y por lo que más le costare de los precios señalados en esta escritura en cada género y partida diferido en su simple juramento se lo ha de pagar el dicho Francisco Javier Dominguez luego que conste $=\mathrm{Y}$ si el dicho $\mathrm{P}$. Comendador le faltare al dicho maestro con la primera paga de los dichos un mil y quinientos pesos y con los socorros que le pidiere y se fueren ofreciendo como dicho es ha de parar en la dicha obra y pagarle todo lo que en ella hubiere hecho y fabricado al respecto de lo que va señalado en cada partida y los materiales que hubiere sueltos en el dicho Convento asi piedra como de cal y ladrillo y todo de contado a expensas de los bienes expolios del dicho M.R.P. Fray Diego Serrano y en su defecto se le ha de hacer juramento quiénes o qué personas tienen y en qué cantidad para que el dicho maestro Francisco Javier Domínguez haga diligencia judicial o extrajudicialmente para la cobranza de todo lo que se le debiere pagar y satisfacer ajustada la cuenta con el dicho Padre Comendador de que se le ha de dar vale firmado de su nombre el cual con esta escritura y su simple juramento ha de ser bastante recaudo para su cobranza ... (siguen cláusulas notariales de obligación)... y consiente que de esta escritura se saquen uno o más traslados el uno cumplido y pagado los demás no valgan en cuyo testimonio los otorgantes lo firmaron de sus nombres juntamente con el dicho M.R.P. Provincial siendo 
a lo que hecho es presentes por testigos el capitán Francisco de Suasnabar don Francisco de Arce y Avendaño y Juan Jácome residentes en esta dicha ciudad

\author{
Fray Sebastián de Pastrana Fray Juan Centeno \\ Provincial \\ Francisco Javier Domínguez \\ ante mí \\ Nicolás García \\ escribano público
}

\title{
TASACION Y APROBACION DE LOS REPAROS DE LA MURALI,A DE LIMA QUE HAN DE HACER ANTONIO DE RUEDA Y EL CAPITAN FRANCISCO PASCUAL DE LOMBA*
}

En la ciudad de los Reyes del Perú en diez y seis días del mes de julio de mil y seiscientos y noventa y ocho años ante mí el escribano y testigos Antonio de Rueda y el capitán Francisco Pascual de Lomba que doy fe conozco y otorgaron ambos juntos labrarán la obra que necesita la muralla de esta ciudad en la forma y manera siguiente

Primeramente el baluarte del río de Monserrate y la cornisa inmediata cuatrocientas y catorce varas de largo en el todo y la cortina que mira al mar y le falta el cordón banqueta y parapeto y de allí para adelante como es los dos frentes de dicho baluarte y el través que mira a la puente le falta una vara hasta ponerlo en el estado de solería cordón banqueta y parapeto que todo hacen ciento y treinta varas del recinto que el Sr. Duque de La Palata pagó en sus principios a veinticuatro pesos y al medio de la obra exclamaron y se les dio a veintisiete pesos por cada vara del recinto que dichas ciento y treinta varas a dichos veinte y siete pesos cada vara montan tres mil quinientos y diez pesos. lio $666 \mathrm{v}$.).

* (A.G.N., escribano Diego Fernández Montano, 1698, protocolo 502, fo- 
Síguese el portillo de Renán Paniagua que tiene que reedificar treinta varas de largo y ocho de alto hasta el parapeto y en consideración que la obra antigua queda parte de ella en ser y hecha la cuenta tiene las sesenta varas de recinto a dichos veinte y siete pesos hacen ochocientos y diez pesos.

Síguese el portillo de San Jacinto que tiene que hacer de adobería cinco varas de recinto que acompañan la albañilería de ladrillo que importa dicha adobería ciento y treinta y cinco pesos y la albañilería de este postigo de ladrillos y cal importa doscientos y sesenta y seis pesos.

Item diez varas cúbicas de cimientos de piedra del río y harro a dos pesos veinte pesos.

Habiéndose de traer de la Tila dos piedras para las quicialeras de la parte de arriba de una vara de largo cada una y tercia de ancho y de peralte otra tercia alierta la quicialera del tamaño que se le diera

Un portillo alto que está en lo alto del Crimen en una cortina de forma triangular tiene una vara de recinto $e$ importa veinte y siete pesos.

El postigo que se ha de macizar en Guadalupe tiene cuarenta varas cúbicas de adobería que hacen dos varas de recinto y valen cincuenta y cuatro pesos.

El portillo de Santa Catalina que se ha de cerrar de adobería tiene cuatro varas de recinto que a veinte y siete pesos vara importan ciento y ocho pesos.

Síguese el postigo del dicho Molino de Santa Catalina que ha de ser de tres varas de ancho con dos pilares a los lados y cada uno de ellos de tres varas de grueso con sus trabazones tres varas de ancho de alto cuatro varas cimiento de piedra y barro de media vara de fondo un brote de madera de amarillo para las quicialeras de cinco varas de largo cinco cuartones de ollar cinta embebida y tabla de roble encima solado de ladrillo revocado con cal las dos surtidas así en la banqueta como en el andén y tres varas de recinto de adobería para el acompañado de dichos pilares por los lados y todo importa seiscientos y cuarenta pesos. 
Síguese la portada de Cocharcas camino real del Arco dejando el hueco de la puerta de cuatro varas y cuarta y cuatro varas para los pilares de los lados que dan de recinto en el acompañado de adobería cinco varas de recinto que montan a los veinte y siete pesos ciento $y$ treinta y cinco pesos.

Y la portada con dos pilares a los lados con basa plinto con una hilada de piedra de cantería al pie y el rudol y media caña alquitrabe a la cornisa y friso bocel y paflón cubierto de cuartones tantos cuantos tienen las otras portadas en toda perfección de ladrillo de corte importa su valor dos mil ochocientos y setenta y seis y las que se hicieron de esta forma en tiempo del Sr. Duque fue su custo de cinco mil pesos.

El parapeto inmediato a la puerta de los Padres Belemitas se ha de poner baqueta cordón parapeto y solería corren diez y siete varas de largo como también las dos subidas en dicha portada y cada subida de seis varas de largo y dos de alto en escarpa hacen seis varas de recinto importan ciento y sesenta y dos pesos

El derrumbe que hizo la acequia que se vertió contra la muralla en la puerta falsa del Cercado tiene de costo quinientos pesos derribando todo lo viciado y haciéndolo de nuevo diez y siete varas que es lo que tiene según lo ha reconocido.

La cual dicha obra fue tasada y apreciada por el Padre Maestro Fray Cristóbal Caballero del Orden Real de Nuestra Señora de Las Mercedes que lo es de Fábricas y por el Ayudante de Ingeniero Pedro de Asensio según la tasación y avaluación de dicha obra firmada de los susodichos de cinco del corriente la cual dicha obra de la muralla de esta ciudad han visto y reconocido los otorgantes y poniéndolo en efecto dichos de por sí in solidum renunciando como expresamente renuncian las leyes de duobus... y todas las demás de la mancomunidad como en ellas se contienen debajo de la cual otorgan que se obligan a hacer la dicha obra que se necesita en la muralla así de una puerta como de un postigo y cerrar los demás portillos que van mencionados en esta escritura cuyas obras contenidas darán acabadas en toda perfección y satisfacción del dicho Padre Presentado y Maestro Mayor de Fábricas Reales o de aquella persona o personas que por su Excelencia se nombraren para su reconocimiento y para los materiales y trabajos se les 
han de dar los nueve mil trescientos y noventa y un pesos de a ocho reales contenidos en la presente escritura que se les han de ir socorriendo por Su Excelencia según lo necesitaren y el resto al fin de acabar la obra.

Y es calidad y condición que si la dicha obra no la hicieren con la perfección y según y como se contiene en la tasación inserta quieren que por lo que dejaren de hacer y faltaren a lo contenido en dicha tasación y avaluación la mande hacer Su Excelencia a su otra persona y por lo que costare más han de poder ser ejecutados en virtud de esta escritura y el reconocimiento o juramento del Maestro Mayor de Fábricas sin otra prueba ni recaudo alguno... (siguen las cláusulas notariales de obligación)... 